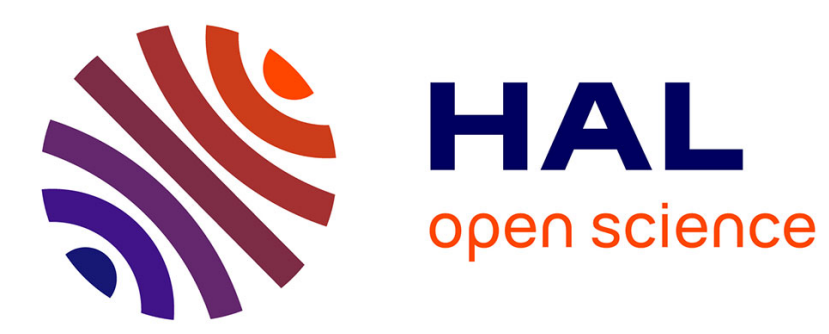

\title{
A review of the photo-thermal mechanism and crystallization of photo-thermo-refractive (PTR) glass
}

\author{
Julien Lumeau, Edgar Dutra Zanotto
}

\section{To cite this version:}

Julien Lumeau, Edgar Dutra Zanotto. A review of the photo-thermal mechanism and crystallization of photo-thermo-refractive (PTR) glass. International Materials Reviews, 2017, 62 (6), pp.348 - 366. 10.1080/09506608.2016.1264132 . hal-01528362

\section{HAL Id: hal-01528362 \\ https://hal.science/hal-01528362}

Submitted on 13 Mar 2019

HAL is a multi-disciplinary open access archive for the deposit and dissemination of scientific research documents, whether they are published or not. The documents may come from teaching and research institutions in France or abroad, or from public or private research centers.
L'archive ouverte pluridisciplinaire HAL, est destinée au dépôt et à la diffusion de documents scientifiques de niveau recherche, publiés ou non, émanant des établissements d'enseignement et de recherche français ou étrangers, des laboratoires publics ou privés. 


\title{
A review of photo-thermo-refractive (PTR) glass
}

\author{
(Suggested by the editors of IMR)
}

Or

\section{A review of the photo-thermal mechanism and crystallization of photo-thermo-refractive (PTR) glass (preferred by the authors)}

\section{Julien Lumeau ${ }^{1}$ and Edgar Dutra Zanotto ${ }^{2}$}

\author{
${ }^{1}$ Aix Marseille Univ, CNRS, Centrale Marseille, Institut Fresnel, Marseille, France \\ ${ }^{2}$ Vitreous Materials Laboratory, Department of Materials Engineering, Federal University of \\ São Carlos, 13565-905, São Carlos, São Paulo, Brazil
}

\begin{abstract}
Photo-thermo-refractive (PTR) glass is an optically transparent photosensitive sodium aluminosilicate glass containing sodium fluoride and potassium bromide along with 100-1000 ppm of silver plus cerium, tin and antimony oxides. UV-exposed regions of this glass produce silver nanoclusters, $\mathrm{NaBr}$ and $\mathrm{NaF}$ nanocrystals upon heating, giving rise to a permanent, localized refractive index change. This is the basis for the production of holograms that can be used as Bragg gratings. In this article, we present a comprehensive overview of the (currently known) photo-thermo-refraction and crystallization processes occurring in photo-thermorefractive glass. We first give a general introduction of PTR glasses and their applications. Then, we perform a thorough analysis of the known mechanisms of refractive index changes in PTR glasses starting with the photoinduced process followed by the crystal nucleation mechanism and
\end{abstract}


NaF crystallization kinetics. Finally, we concentrate on the PTR glass nanostructure and its effect on the crystallization mechanisms and properties, finishing with the crystallization kinetics and origin of the refractive index change in PTR glass. Despite the fact that much is known about this septuagenarian glass and that it is already being commercially produced, a number of open problems still exist that warrant further investigation. 


\section{Introduction}

Photo-thermo-induced crystallization in multicomponent fluorosilicate glasses doped with 100-1000 ppm of Ce, Ag, Sb and Sn was invented in 1949 by S. D. Stookey at Corning Glass Works [1] (Figure 1). In this technology, photo-thermo-induced precipitation of metallic Ag allowed the production of grey or black glasses, whereas the precipitation of $\mathrm{NaF}$ nanocrystals in UV-exposed areas allowed for the production of white opaque (partially crystallized) glass plates. Photo-thermo-induced crystallization paved the way for black-and-white photography in a glass interior. However, despite these interesting results, no real commercial applications were immediately determined. Thirty years later, the same inventor Stookey demonstrated [2] that additional UV exposure and thermal development of a similar glass resulted in precipitation of additional metallic Ag particles on top of the NaF crystals. These particles produced different colors depending on the UV dosage. These new results laid the groundwork for full color image recording. However, it was only after 35 years of study and development of this class of glasses that uniformly spaced variation of the refractive index correlating with the precipitation of $\mathrm{NaF}$ nanocrystals was revealed, but it was again thought to be insufficient for practical applications [3]. A few years later, in the late 1980s, this effect was re-investigated, and uniformly spaced refractive index variation in a glass interior was re-discovered and applied to the recording of the first hologram in glass using the photo-thermo-refraction (PTR) phenomenon [4]. This discovery was associated with the appearance of high quality UV lasers (He-Cd lasers) and was the starting point for a large number of improvements in this class of glasses, which resulted in recording of the first holograms in PTR glasses with moderate diffraction efficiency [5], and then the production of the first high-efficiency volume Bragg grating in PTR glass [6-8]. Today's technology allows for the fabrication of holograms in PTR glasses with diffraction efficiencies of 
up to $99.9 \%$, absorption in near IR of $1-2 \times 10^{-4} \mathrm{~cm}^{-1}$ [9], scattering down to $5 \times 10^{-3} \mathrm{~cm}^{-1}$ and aperture up to $50 \times 50 \mathrm{~mm}^{2}$, which enabled a dramatic increase in the performance of laser systems. The current level of PTR glass technology allows for the production of PTR glasses with absorption in the near IR region of $5 \times 10^{-5} \mathrm{~cm}^{-1}$, refractive index fluctuations of only $10^{-5}$, and apertures up to $100 \times 100 \mathrm{~mm}^{2}$. With such high quality, volume Bragg gratings have become commercially available. At least three US companies are selling such products: OptiGrate [10], Ondax [11] and PD-LD [12]. PTR glass mainly allows for the production of four types of optical elements: transmitting Bragg gratings [13,14], reflecting Bragg gratings [15,16], chirped Bragg gratings $[17,18]$ and phase plates $[19,20]$. Photosensitive fibers made out of PTR glass have also been reported [21]. These elements are used for a wide range of applications [22-24]. Thanks to their high angular selectivity [25], transmitting Bragg gratings have been thoroughly used for the selection of transverse mode and phase locking of multimode lasers [26,27]. Reflecting Bragg gratings have shown a wide range of applications, such as notch filters for Raman spectroscopy [28], external couplers for longitudinal mode selection in laser systems $[29,30]$, or angularly and spectrally selective elements in spectral or coherent beam combining of high energy lasers [3134]. Finally, chirped Bragg gratings have been shown to be versatile and efficient for stretching (up to $1 \mathrm{~ns}$ ) and compression of ultra-short pulse lasers and are a very promising alternative to standard systems based on planar diffraction gratings [35,36]. It is also important to stress that the use of PTR glasses has also been reported for other applications. For example, doping of PTR glass with rare earth ions $(\mathrm{Nd}, \mathrm{Yb}$ and $\mathrm{Er})$ has been reported $[37,38]$, and their use for the fabrication of distributed Bragg reflector lasers and distributed feedback lasers was demonstrated $[39,40]$. Additionally, the use of PTR glass as a photo-etchable glass was recently demonstrated [41] as well as ion-exchange [42]. 
On the basis of this wide range of applications involving high energy laser systems, there is a fast growing demand by industries interested in this technology. As of today, various commercial laser products have integrated these volume Bragg gratings, especially semiconductor lasers (for example, see [43]).

The number of publications on PTR glass and its applications significantly increased until 2007 and then stabilized to approximately 20 to 30 papers per year. Figure 2 shows the number of articles published since 1951 with the keywords ("photo-thermo-refractive" or PTR) and glass* in the article title, abstract or keywords in the Scopus database. There are also dozens of granted and filled patents on PTR glass technology confirming the high impact and potential of this technology.

The high interest in PTR glass technology relies on the fact that these glasses combine large permanent refractive index changes, with low optical losses and high stability. However, despite this apparent maturity, the mechanisms involved in refractive index variation in this very complex, 13-component glass are far from being fully understood. Four short review papers have already been published on PTR glass [44-47]. Two of them are approximately 10 years old and the other two are about 15 - 20 years old, and they focused on optical properties. Additionally, as we mentioned previously, very significant progress in this field has been achieved over the past 10 years. The goal of this paper is to review the general knowledge on the PTR glass photothermal mechanisms and crystallization processes, as they stand today, to reveal outstanding problems that appear as natural directions for future researches.

Before describing the processing and resulting properties, let us first analyze the composition of PTR glass. The batch composition of a typical PTR glass is shown in Table 1. 
This glass contains 13 elements, including four dopants ( $\mathrm{Ce}, \mathrm{Ag}, \mathrm{Sb}$ and $\mathrm{Sn}$ ) and two highly volatile elements ( $\mathrm{F}$ and $\mathrm{Br}$ ). Cerium is the photo sensitizer, i.e., the element used to produce electrons during its interaction with actinic photons [48]. Ag is an element that is supposed to be a nucleating agent [49] (the classical view), but its exact contribution to the PTR glass crystallization mechanism remains unclear as we will show later. Antimony is used to remove bubbles during the melting stage [50] but also, in combination with tin, to maintain a proper redox ratio between the multi valent ionic species [51]. Basically, the glass must contain a fair fraction of $\mathrm{Ce}^{3+}$ and $\mathrm{Ag}^{1+}$ ions, whereas the two highly volatile elements are supposed to be key for the crystallization process. Other types of PTR glass with slightly different compositions have also been reported. For instance, Wang et al. [52] reported a PTR glass containing $\mathrm{B}_{2} \mathrm{O}_{3}$, and Dubrovin et al. [53] reported Cl-based PTR glass. Various concentrations of silver have also been reported [53,54] as well as glasses without $\mathrm{SnO}_{2}$ [55]. Finally, some types of PTR glass based on the crystallization of $\mathrm{CaF}_{2}$ or $\mathrm{BaF}_{2}$ have also been reported [56-59]. These glasses are very promising as they should offer lower scattering losses due to a smaller refractive index mismatch between the glass matrix and the nanocrystals, but no clear evidence of photo-induced refractive index change has been reported for these compositions. However, the overall behavior of these PTR glasses is not significantly different from that of the traditional PTR glass that is currently commercialized. This paper therefore concentrates on the properties of the regular PTR glass composition.

A significant section of this paper will be dedicated to the role of the multivalent and volatile elements in the photo-thermo-induced process. At this stage, it is important to stress that, to the best of our knowledge, the exact composition (after melting) of PTR glass has not been reported throughout these years. First, one must keep in mind that the concentration of the volatile 
elements is expected to fluctuate from one melt to another depending on the exact melting conditions and atmosphere (the typical schedule is $\mathrm{T}_{\text {melt }}$ at approximately $1450{ }^{\circ} \mathrm{C}$ for 2 hours in air). Then, the accurate determination of the concentration of these elements, as well as of the dopants, is very challenging. One particular technique has been frequently used over the past ten years: secondary ion mass spectroscopy (SIMS) [60,61]. This technique was shown to be adequate for comparisons of the relative concentrations of the elements from glass to glass batch for both amorphous and crystalline species but not for the absolute determination of the concentration of each species in PTR glass [60,61]. SIMS was used, for example, to show that volatilization of some elements (especially fluorine) occurs even at the relatively low temperatures used for producing volume Bragg gratings in PTR glass. By combining optical microscopy and SIMS, Lumeau et al. [62] have shown that, during a thermal treatment at 520 ${ }^{\circ} \mathrm{C}$, a 10 to $20 \mu \mathrm{m}$ depleted layer appears at the surface of a PTR glass, leaving a layer with a modified glass composition where no crystallization (of NaF) takes place. This effect was recently confirmed by measuring waveguide modes in the depleted layers [63]. Such an effect was then demonstrated to have a very strong impact on the quality of the volume Bragg gratings due to resulting warping of the glass plates [64].

Spectroscopic analysis methods were also developed to analyze some of the ionic species [65]. However, the inability to provide an accurate read of the actual composition of the studied PTR glass is still a key open issue when studying such a glass. In ref. [62], Lumeau et al. proposed a new method to gauge, at different scales, the optical and crystallization homogeneity of photosensitive optical glasses and tested it with photo-thermo-refractive glass. This method was based on the association of different techniques: Zygo interferometry, which permits mapping the evolution of the optical (average chemical) heterogeneity over the sample, and non- 
isothermal differential scanning calorimetry and optical microscopy for gauging the crystallization homogeneity at centimeter, millimeter and micrometer scales. Quantitative characterization of crystallization homogeneity using Poisson statistics was also employed. The authors used this method to obtain a direct quantitative evaluation of the degree and scale of the crystallization homogeneity in the glass. This study demonstrated that, regardless of the scale, a significant degree of chemical heterogeneity occurs in PTR glass (although PTR glass remains one of the most homogeneous glasses ever made at laboratory scale). The discussion presented above makes it clear that studying this complex glass is quite challenging. However, despite the relative ignorance regarding the exact details of the photo-thermo-refractive process, today's technology of PTR glass melting allows one to achieve optical quality glass with reproducible properties. 
Now that we have discussed the basic composition of PTR glasses, let us describe the basic processes of photo-thermo-induced structural transformations in PTR glass (Figure 3). A simplified (classical) model can be described as follows:

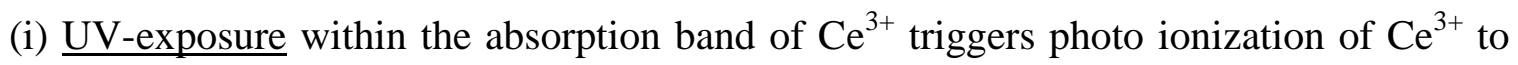
$\mathrm{Ce}^{4+}$ and one electron; the latter is trapped by an ionic silver atom to yield an atomic silver atom [66]. At this stage of the process, photoionization causes additional absorption and an increment of the refractive index by approximately $10^{-6}$. However, exposure of UV-exposed glass to high power (nanosecond regime, $>1 \mathrm{MW} / \mathrm{cm}^{2}$ ) visible radiation causes bleaching of such prenucleation centers [67].

(ii) The second stage occurs after heating a UV-exposed sample to $490^{\circ} \mathrm{C}$ and consists of the creation of nucleation centers, which include $\mathrm{Ag}^{0}$ and perhaps $\mathrm{AgBr}[68,69]$.

(iii) Then, further heating to $520{ }^{\circ} \mathrm{C}$ results in the heterogeneous precipitation of cubic $\mathrm{NaF}$ on top of the previously formed $\mathrm{Ag}^{0}$ or $\mathrm{AgBr}$ [70]. Cooling of the glass sample to room temperature induces residual internal stresses caused by the difference in the coefficients of thermal expansion of the NaF crystals and the residual PTR glass matrix, which have been associated with an induced refractive index decrement of approximately $10^{-3}$ [71] (measured through the photo elastic properties of the glass [72]). Within this paper, we propose to detail each of these steps to give a critical overview of the photo-thermo-refractive process.

\section{The photoinduced process}

The first step for the excitation of photosensitivity is the interaction between light and the glass. There are two types of interactions: linear and non-linear. For linear interactions, cerium is a key element in PTR glass, as it plays the role of photo sensitizer. Cerium has two different 
valence states in glass, $\mathrm{Ce}^{4+}$ and $\mathrm{Ce}^{3+}$, inducing absorption in the $\mathrm{UV}$ region with a wide ceric peak centered at approximately $240 \mathrm{~nm}$ and a relatively narrow asymmetrical cerous peak with a maximum approximately 300-320 nm [73]. However, spectroscopic studies of cerium in glasses encounter some difficulties because of the overlapping of these bands. In addition, redox equilibria in silicate glasses are rather complex and depend on many factors (host-glass composition, temperature, oxygen ion activity and the total number of multivalent ions present) [74]. However, $\mathrm{Ce}^{3+}$ and $\mathrm{Ce}^{4+}$ are almost always present in Ce-doped silicate glasses even under very strong reducing or oxidizing conditions. For the overlapped absorption spectra of $\mathrm{Ce}^{3+}$ and $\mathrm{Ce}^{4+}$ to be separated, a new approach was used in refs. [75,76], which was based on a reliable algorithm for resolving experimental spectra into characteristic spectra of cerous, ceric and intrinsic glass absorption. PTR glasses with regular composition, i.e., $70 \mathrm{SiO}_{2}-15 \mathrm{Na}_{2} \mathrm{O}-5 \mathrm{ZnO}-$ $4 \mathrm{Al}_{2} \mathrm{O}_{3}-5 \mathrm{NaF}-1 \mathrm{KBr}$ and $0.008 \mathrm{~mol} \%$ cerium doping were melted under different redox conditions. A total of four glass samples were prepared: undoped glass matrix and Ce-doped glasses melted in air (standard conditions) and under an oxidizing and reducing atmosphere. The absorption spectra of undoped $\left(\mathrm{PTR}_{\mathrm{m}}\right)$ and Ce-doped $\left(\mathrm{PTR}_{\mathrm{Ce}, \mathrm{s}}\right)$ PTR glasses melted in air were measured using a Varian Cary 500 spectrophotometer and are illustrated in Figure 4. The absorption spectrum of cerium was derived by subtraction of the undoped glass spectrum from that of the Ce-doped glass. In the absorption spectrum of cerium, the band with a maximum located near $240 \mathrm{~nm}$ is usually ascribed to $\mathrm{Ce}^{4+}$ and the band with a maximum approximately $305 \mathrm{~nm}$ to $\mathrm{Ce}^{3+}$. Similar spectra were measured in PTR glasses melted under different conditions but with different ratios for the $\mathrm{Ce}^{3+}$ and $\mathrm{Ce}^{4+}$ bands. By using a linear combination, the authors showed that it is possible to separately extract the $\mathrm{Ce}^{3+}$ and $\mathrm{Ce}^{4+}$ bands. Then, each band was modeled using a sum of two elementary Gaussian curves as summarized in Table2. 
It is interesting to note that a similar approach was used by Nikonorov et al. [77-79], who found very similar shapes for $\mathrm{Ce}^{3+}$ and $\mathrm{Ce}^{4+}$ but showed that they need not only two but three curves for fitting the $\mathrm{Ce}^{3+}$ and $\mathrm{Ce}^{4+}$ absorption bands (Table 3). It must be noted that the additional band they added has a very low amplitude comparable to the accuracy of the measurement. However, very recent work aimed at accurately measuring the absorption spectra of thick pristine PTR glass has shown that $\mathrm{Ce}^{3+}$ tends to have a long exponential tail up to $370+\mathrm{nm}$, and therefore, the modeling of cerium absorption bands is most likely a complex process that requires at least 2 or 3 Gaussian bands and also an exponential component following the Urbach rule [80].

One must recall that cerium is often used in silicate glasses as a photo sensitizer. In the case of PTR glass, the linear photo-thermo-refractive process under UV excitation exists only because of cerium [65]. Therefore, a detailed analysis of the effect of UV light on the structure of the absorption band of cerium is extremely important. In ref [67], regular PTR glass samples were exposed to radiation of a $\mathrm{He}-\mathrm{Cd}$ laser at $325 \mathrm{~nm}$ to dosages of $5 \mathrm{~J} / \mathrm{cm}^{2}$. Absorption spectra were measured after UV exposure and thermal treatment (one hour at $100^{\circ} \mathrm{C}$ ) to bleach transient color centers. A thorough study of the color centers in PTR glass can be found in several papers $[81,82]$ but is beyond the scope of this article. During this UV exposure, photoionization of $\mathrm{Ce}^{3+}$ to $\mathrm{Ce}^{4+}$ is expected to occur. If this supposition is true, each $\mathrm{Ce}^{3+}$ that disappears would be converted to a new $\mathrm{Ce}^{4+}$ ion and the band of $\mathrm{Ce}^{4+}$ would increase accordingly. However, this supposition could not be confirmed when trying to separate the contributions of $\mathrm{Ce}^{3+}$ and $\mathrm{Ce}^{4+}$, and decomposition into Gaussian functions revealed that UV exposure did not induce any increase in the $\mathrm{Ce}^{4+}$ absorption band but rather induced a broad band that can be fitted with a single Gaussian function with a maximum at approximately $242 \mathrm{~nm}$ for PTR glass. The 
wavelength of this band remains unchanged irrespective of the increase of the dosage, whereas its amplitude increases with increasing dosage. This induced band was attributed to hole centers $\left(\mathrm{Ce}^{3++}\right)$ and electrons (e $\left.\mathrm{e}^{-}\right)$formed during the ionization process:

$$
C e^{3+}+h v \rightarrow C e^{3++}+e^{-}
$$

This result showed that the photochemistry of cerium in silicate glass is rather complex and justifies the approach of separating the contribution of each ion and decomposing them into a sum of Gaussian functions. An additional study was performed by Chamma et al. [83].To confirm the presence of multiple (at least 2) types of cerium, they exposed PTR glasses in two different regions, i.e., similarly to Anne et al. [65] at $325 \mathrm{~nm}$, where both Gaussian functions for $\mathrm{Ce}^{3+}$ overlap, and at $266 \mathrm{~nm}$, where only one Gaussian function contributes to the absorption of $\mathrm{Ce}^{3+}$. Then, cerium-induced spectra were calculated after UV-exposure by subtracting the absorption spectrum after UV exposure from the spectrum before any exposure (Figure 5). It is seen that the induced absorption spectra differ depending on whether 266 or $325 \mathrm{~nm}$ is used for exposure with the overall amplitude of the induced absorption bands being proportional to the exposure dosage. Some decomposition of the induced absorption bands revealed that in the 220$290 \mathrm{~nm}$ range, two bands at 238 and $276 \mathrm{~nm}$ appear that can be ascribed to $\mathrm{Ce}^{3++}$, as they do not correspond to any known intrinsic color center. Similarly, an analysis of the induced absorption in the $315-350 \mathrm{~nm}$ range showed that two bands at 317 and $332 \mathrm{~nm}$ appear, which can be ascribed to $\left[\mathrm{Ce}^{4+}\right] \mathrm{e}^{-}$as they also do not correspond to any known intrinsic color center. Finally, in the $220-290 \mathrm{~nm}$ range, additional induced absorption bands are created. In conclusion, ionization of cerium results in a very complex redox equilibrium between all the presented species that can be summarized as follows:

$$
\text { 1. } \mathrm{Ce}^{3+}+\mathrm{h} v \rightarrow \mathrm{Ce}^{3++}+1 \mathrm{e}^{-} \quad \text { where } \mathrm{Ce}^{3++} \neq \mathrm{Ce}^{4+}
$$




$$
\begin{aligned}
& \text { 2. } \mathrm{Ce}^{4+}+1 \mathrm{e}^{-} \rightarrow\left[\mathrm{Ce}^{4+}\right] \mathrm{e}^{-} \quad \text { where }\left[\mathrm{Ce}^{4+}\right] \mathrm{e}^{-} \neq \mathrm{Ce}^{3+} \\
& \text { 3. }\left[\mathrm{Ce}^{4+}\right] \mathrm{e}^{-}+\mathrm{h} v \rightarrow \mathrm{Ce}^{4+}+1 \mathrm{e}^{-}
\end{aligned}
$$

It is important to note that the previous studies were performed on glasses with only one ionic doping species. However, in regular PTR glass, $\mathrm{Sn}, \mathrm{Sb}$ and $\mathrm{Ag}$ ions are also present. Therefore, in addition to the first three reactions presented above, the first basic reactions are as follows [84]:

3. $\mathrm{e}^{-}+\mathrm{Ag}^{+} \rightarrow\left(\mathrm{Ag}^{+}\right)^{-}$

4. $\mathrm{e}^{-}+\mathrm{Sn}^{4+} \rightarrow\left(\mathrm{Sn}^{4+}\right)^{-}$

5. $\mathrm{e}^{-}+\mathrm{Sb}^{5+} \rightarrow\left(\mathrm{Sb}^{5+}\right)^{-}$

One must also keep in mind that despite the very low level of contamination of these glasses, iron is, for example, still present in these glasses at the level of approximately1 ppm and is also an electron acceptor $[9,84]$ :

$$
\mathrm{e}^{-}+\mathrm{Fe}^{3+} \rightarrow\left(\mathrm{Fe}^{3+}\right)^{-}
$$

Although this reaction most likely has a negligible contribution to the photo-thermoinduced process, it has a major impact on the near-IR absorption of the glass [9].

Actually, according to Nikonorov et al. [84,85], electrons are not essentially trapped by silver ions as presented in Figure 3 but rather by $\mathrm{Sb}$ ions during room temperature exposure. Then, electrons are only transferred to silver ions to form silver atoms at the first stages of the heat treatment of PTR glasses. Very recently, Magon et al. [86] performed detailed EPR measurements on PTR glasses with different dopants and indeed confirmed that electrons are initially transferred to $\mathrm{Sb}$ ions at room temperature. They also showed that these species are transient and that electrons are then transferred to $\mathrm{Ag}$ ions as soon as the temperature is increased to a few hundred degrees. Their results show that, due to the numerous ionic species within PTR 
glass, the photoionization process in PTR glass is indeed more complex than anticipated by the traditional mechanism with each type of multivalent ion playing a very specific role.

Up until now, we have reviewed the basic mechanisms that originate linear PTR glass photosensitivity. However, some additional work studied the nonlinear photosensitivity of PTR glasses. It was shown in ref. [87] that two-photon ionization of the PTR glass could be achieved using the third harmonic of a Nd:YAG laser at $355 \mathrm{~nm}$. It is important to stress that some authors also demonstrated that two photon absorption of cerium ions was not possible; therefore, it was not due to the multivalent ions but instead ionization of the glass matrix. Hence, the cerium ions are not needed for this process. In a more recent unpublished work, Glebov's group showed that, when using pulses from a nanosecond laser at $355 \mathrm{~nm}$, both linear and non-linear photoionization occur and that both linear and non-linear photosensitivity can be used for the recording of phase elements. Their observation correlates with the presence of a long wavelength tail of the cerium absorption band, as discussed earlier. Similarly, multi-photon ionization of the PTR glass matrix was shown to be possible using a weakly focused femtosecond laser with central wavelength anywhere between 800 and $1500 \mathrm{~nm}$ and a peak intensity of $10^{13} \mathrm{~W} / \mathrm{cm}^{2}[88,89]$. Mechanisms of this non-linear interaction were studied in detail using the Franz Keldysh theory [88] and apparently result from a complex interaction combining multi-photon and tunneling ionization. Finally, very recent work has shown that it is possible to replace $\mathrm{Ce}$ by $\mathrm{Tb}$ ions, and that dual wavelength illumination (UV and a longer wavelength) allows one obtaining PTR glasses with photo sensitivity at longer wavelengths, i.e. in the visible and near-IR ranges due to an up conversion process [90]. Finally, it is important to stress that whatever process is used for triggering photosensitivity in PTR glass (linear, non-linear, up-conversion...), all further thermal 
processes occurring in that glass will remain the same as that used after exposing PTR glass with a He-Cd laser.

In summary, we have shown that the first basic process of the PTR glass linear photosensitivity based on the ionization of cerium ions is, in fact, a very complex one due to the complicated structure of the absorption bands of cerium and also due to the presence of numerous multivalent ions in the glass that are necessary for the photo-thermo-induced process to occur.

\section{Crystal nucleation mechanism in PTR glass}

After the glass has been UV exposed, the second step is a heat treatment that allows for the creation of nucleation centers $\left(\mathrm{Ag}^{0}, \mathrm{AgBr} \ldots\right)$ for the $\mathrm{NaF}$ crystals. Nucleation has been studied using direct and indirect methods. The first reported data were obtained by non-isothermal differential scanning calorimetry (DSC). Lumeau at al. [91] reported data on the effect of a nucleation heat treatment on the position of the glass transition temperature $\left(T_{g}\right)$ and the crystallization peak temperature $\left(T_{c}\right)$ on both unexposed and UV-exposed PTR glasses. They found that there is a common behavior regardless of the original $T_{g}$ and $T_{c}$ of the original glass. Increasing the nucleation temperature at a constant duration or increasing the nucleation duration at a constant temperature results in no change to the $T_{g}$ but leads to a decreased $T_{c}$. Data for $T_{c}$ are summarized in Figure 6. First of all, there is a comparable induction time for both unexposed and UV-exposed glasses. Then, $T_{c}$ decreases for both glasses but saturates at different levels. For a heating rate of $30 \mathrm{~K} / \mathrm{min}, T_{c}$ of the $\mathrm{UV}$-exposed glass decreases from its original temperature (generally above $700{ }^{\circ} \mathrm{C}$ ) to $600 \pm 5{ }^{\circ} \mathrm{C}$, whereas the $T_{c}$ of unexposed glass decreases to $650 \pm 5$ ${ }^{\circ} \mathrm{C}$. In other words, by applying adequate thermal treatments, the so-called nucleation-induced 
photo-crystallization (i.e., crystallization in UV-exposed regions) happens faster than the pure thermally-induced spontaneous crystallization (i.e., crystallization in UV-unexposed regions), which allows for inducing a refractive index change only in UV-exposed regions. This phenomenon is at the basis of all the volume Bragg gratings recorded in PTR glasses. It is also important to note that an additional DSC peak sometimes appears in both unexposed and UVexposed nucleated PTR glass samples at the same temperature of $625 \pm 5^{\circ} \mathrm{C}$. Additional studies performed by non-isothermal DSC [92] have concluded that this additional peak, or shoulder, in PTR glass crystallization peaks, which sometimes appears in the non-isothermal thermograms, reflects superimposed effects of an exothermal event of $\mathrm{NaF}$ crystal formation and the endothermal event related to a relaxation mechanism of the matrix. This aspect will be reinvestigated in the next section, where the structure of a (partially) crystallized glass will be analyzed.

In addition to DSC, the detailed kinetics of NaF crystallization in UV-unexposed PTR glass was experimentally studied using optical microscopy [93]. Steady-state nucleation rates, nucleation time-lags and crystal growth rates were estimated in a temperature interval covering almost three hundred degrees from a $T_{g}$ of approximately $470{ }^{\circ} \mathrm{C}$ up to $750{ }^{\circ} \mathrm{C}$. A self-consistent description of these data in the framework of Crystal Nucleation Theory was presented using the interfacial free energy and the effective diffusion coefficient as adjustable parameters. The diffusivities calculated from crystallization kinetics and viscous flow undergo a decoupling phenomenon, which was already demonstrated for other fragile glasses. More precisely, it was shown that the nucleation rates increase up to a temperature of approximately $485{ }^{\circ} \mathrm{C}$, where a maximum is reached, and then decrease when the temperature is further increased. This result indicates that $485^{\circ} \mathrm{C}$ is the optimal temperature for abundant nucleation in PTR glass. 
Now it becomes essential to understand the nucleation mechanisms in UV-exposed PTR glass. From the classical point of view, silver clusters are formed during the first stages of the heat treatment and act as nucleation centers for $\mathrm{NaF}$ crystals. For this assumption to be analyzed further, optical spectroscopy studies should be conducted, as previously described. It is wellknown that metallic nanoparticles result in the appearance of a plasmon resonance, typically in the blue-green region of the spectrum for Ag-containing particles. The evolution of the absorption band of those particles was studied during the nucleation process at $485{ }^{\circ} \mathrm{C}$ [68]. It was shown that the broad band is not a single one but rather results from superposition of several elementary bands. More precisely, this band was decomposed with a sum of four Gaussian bands, two of which require long wavelength Urbach tails. These bands were associated with hole centers, silver, silver bromide and silver bromide with a silver shelf (silver/silver bromide) particles [54,84,94-97]. A complex evolution of each band during the nucleation process was revealed by combining spectrophotometric measurements of samples heat-treated for different durations at $485{ }^{\circ} \mathrm{C}$ and decomposition into elementary Gaussian bands [68]. Then, this behavior was compared with that of the DSC nucleation study [91]. From this analysis, it was shown that the band of silver/silver bromide has maximum amplitude when the DSC crystallization peak temperature reaches its minimum, and therefore, nucleation is expected to have reached its maximum rate.

The authors therefore associated these silver/silver bromide particles with catalyzers of the nucleation process. Then, it is worth noting that after performing an optimized nucleation step at $485^{\circ} \mathrm{C}$ (typically 100 minutes), further heat treatment at a temperature above this temperature (to grow NaF crystals) did not result in any significant evolution of the silver-containing particles absorption band. Although the presence of these silver particles was shown to be mandatory for 
the photoinduced crystallization to happen, more complex phenomena were also revealed. In ref. [98], Lumeau et al. studied the evolution of this silver band in situ at a high temperature during the nucleation process. It was shown that the first elements to appear are silver particles. However, these silver particles are quickly converted into silver bromide. As soon as the maximum amplitude of the silver bromide particles absorption band is reached, no real evolution of the spectra at high temperature occurs. However, significant changes were observed at low temperatures when samples were cooled below a critical temperature situated between 400 and $500{ }^{\circ} \mathrm{C}$. Actually, it was shown that below this critical temperature a band of silver/silver bromide appears and that its intensity depends on the nucleation duration. However, those particles were shown to not exist at temperatures above this critical temperature. It is important to note that the melting point of macroscopic $\mathrm{AgBr}$ crystals is approximately $430{ }^{\circ} \mathrm{C}$ [99], but this temperature is lower for nanoparticles [100]. This process was thus associated with the phase change of the silver/silver bromide nuclei (from liquid to solid) that appears during the cooling or heating processes.

These results could be analyzed in parallel to those reported in ref. [101]. The authors showed that cooling to a temperature below $400{ }^{\circ} \mathrm{C}$, between the nucleation and growth treatments, is a mandatory step to achieve the full benefits of the nucleation heat treatment. A non-isothermal DSC study associated with in-situ pre-nucleation treatment showed that prenucleation enhances crystallization only if the temperature is decreased below $T_{g}$ before the second (development) treatment. Microscopy analysis showed similar results. Performing multistage heat treatment resulted in a large number of small crystals, whereas a single heat treatment with duration equal to the sum of the duration of each heat treatment results in crystals with much larger diameters (Figure 7). 
In summary, we have shown that nucleation is a very complex phenomenon, especially in PTR glass. The nucleation kinetics of PTRG was fully characterized, and an optimal nucleation procedure could be designed. The particles associated with the crystallization enhancement in UV-exposed PTR glass were determined; however, the exact mechanisms are still unclear, especially the physical and chemical nature of the nuclei.

\section{NaF crystallization kinetics in PTR glass}

After analyzing the nucleation mechanisms in PTR glass, we now analyze the processes that occur when the temperature is increased further. It is first obvious that the main effect at relatively low temperatures of thermal treatment, somewhat above $T_{g}$, is the precipitation and growth of NaF crystals. The growth kinetics were recently studied by Dyamant et al. [93], who showed that the growth rate continuously increases from 460 to $760{ }^{\circ} \mathrm{C}$. They measured the actual growth rate between 580 and $650{ }^{\circ} \mathrm{C}$ using only the initial part of the crystal radius versus time plots because in the early stages of the phase transformation crystal growth is determined by a time-independent effective diffusion coefficient. They showed that the growth rate increases from $2 \times 10^{-10}$ up to $2 \times 10^{-8} \mathrm{~m} / \mathrm{s}$. At this stage, it is important to justify why the growth rate determinations were limited to this upper temperature. In ref. [102], Fokin et al. studied NaF solubility, as this parameter combined with the composition of the parent glass determines the super saturation and, hence, the thermodynamic driving force for crystallization. NaF solubility was studied by estimating the equilibrium volume fraction of crystallized $\mathrm{NaF}$ as a function of temperature. For the composition of regular PTR glass, $T_{d s}$, the temperature at which all NaF is dissolved, was shown to be approximately $760{ }^{\circ} \mathrm{C}$. As the crystallized volume increases at $T<T$ ${ }_{d s}$, the super-saturation of a PTR melt, regarding the NaF content, decreases. When the NaF 
content in the residual melt reaches the solubility corresponding to that temperature $\left(T<T_{d s}\right)$, crystallization stops, and the crystallized volume remains unchanged, which is in equilibrium with the $\mathrm{NaF}$ dissolved in the residual glass matrix. This equilibrium volume of the crystalline phase increases with decreasing temperature. For the studied PTR glass composition, the solubility of $\mathrm{NaF}$ approached zero at $T \cong 430{ }^{\circ} \mathrm{C}$.As follows from the discussions above, the thermodynamic driving force for crystallization depends not only on the temperature (as in the case of stoichiometric crystallization) but also on the evolution of the crystallization process that leads to a decrease of supersaturation. As shown in ref. [103], a decrease in supersaturation causes a sharp decline in NaF crystal growth in PTR glass during isothermal heat treatment.

The nucleation rates are, to a great extent, more sensitive to supersaturation than the crystal growth rates. This is the reason why preliminary growth of crystals, and the associated decrease of supersaturation in diffusion zones, can suppress or completely halt the succeeding $\mathrm{NaF}$ nucleation in those zones, as observed in ref. [103]. One should recollect that the commonly accepted scheme assumes heterogeneous nucleation of $\mathrm{NaF}$ catalyzed by the preliminary precipitated silver clusters. However, as already noted, unexposed PTR glass without Ag clusters also undergoes volume crystallization of $\mathrm{NaF}$.

The accepted scheme was idealized for PTR glass after exposure to UV light. However, in any case, if the thermodynamic driving force for crystallization of $\mathrm{NaF}$ approaches zero (i.e., for $T>T_{d s}=745^{\circ} \mathrm{C}$ ) the formation of NaF crystals is thermodynamically impossible and hence any other factors that could foster crystallization (e.g., Ag crystalline clusters) will not be able to participate in the crystallization process. The effect of the other volatile element was also studied and in particular bromine. Nikonorov et al. showed that bromine as a reducing agent affects not only the equilibrium between different silver forms in the glass but also the ratio between the 
forms of optical sensitizer in favor of an increase in $\mathrm{Ce}^{3+}$, the lower the bromine concentration, the lower the $\mathrm{Ce}^{3+}$ concentration [104]. He also showed that the number of free $\mathrm{F}^{-}$ions is also related to the concentration of bromine, thus affecting the crystallization process. This hypothesis was confirmed by Souza et al. [105] who performed a systematic study on the influence of bromine on the crystallization process and showed that bromine decreases the solubility of $\mathrm{NaF}$, i.e., increases the supersaturation of $\mathrm{NaF}$, thus increasing the thermodynamic driving force for crystallization. This feature causes a decrease of the maximum volume fraction of crystallized $\mathrm{NaF}$ with decreasing bromine content in the parent glass.

In ref. [102], the evolution of the glass transition temperature, $T_{g}$, with increasing isothermal treatment time was followed. This evolution revealed a minimum that resulted from the interplay between two concurring processes; liquid-liquid phase separation, which led to a decrease in $T_{g}$, and $\mathrm{Br}$-controlled $\mathrm{NaF}$ crystallization, which acted in the opposite direction. This result is crucial because it shows that PTR glass also undergoes simultaneous liquid-liquid phase separation $[102,106]$. This effect was expected because the main components of this glass are silicon and sodium oxides $\left(15 \mathrm{~mol} . \% \mathrm{Na}_{2} \mathrm{O}\right.$ and $\left.70 \mathrm{~mol} . \% \mathrm{SiO}_{2}\right)$. The critical point of the immiscibility domain is that the $\mathrm{Na}_{2} \mathrm{O}-\mathrm{SiO}_{2}$ system corresponds to $7.5 \mathrm{~mol} . \% \mathrm{Na}_{2} \mathrm{O}$ at $835{ }^{\circ} \mathrm{C}$ [107], but fluorine can extend the immiscibility range [108]. For understanding what glass phase $\left(\mathrm{SiO}_{2}\right.$-rich droplets or the matrix glass) solubility is relevant, evolution of the glass transition temperature was studied at $650{ }^{\circ} \mathrm{C}$ as measured by non-isothermal DSC [102]. In Figure 8, the kinetics of liquid phase separation was separated from that of $\mathrm{NaF}$ crystallization. $T_{g}$ values relate to the glass matrix that has the lowest viscosity (and lowest $T_{g}$ ). It seems that the kinetics of liquidliquid phase separation is initially faster than that of $\mathrm{NaF}$ crystallization. This leads to a hasty decrease of $T_{g}$ during the initial stages of phase transitions in PTR glass. The fact that, after this 
small decrease, $T_{g}$ strongly increases with increasing volume fraction of $\mathrm{NaF}$ crystals gives indirect evidence for crystallization in the glass matrix (not in the droplets) because the formation of $\mathrm{NaF}$ crystals renders the glass matrix poorer in $\mathrm{Na}$ and $\mathrm{F}$, i.e., with higher $T_{g}$. A thorough study combining XRD, SEM, electrical conductivity and optical microscopy revealed the different regimes of LLPS. Heat treatments at temperatures higher than $760{ }^{\circ} \mathrm{C}$ and lower than $925^{\circ} \mathrm{C}$ resulted in the separation of initially homogeneous parent PTR glass into two glassy phases. The droplet-like structure is typical of liquid immiscibility within the metastable region

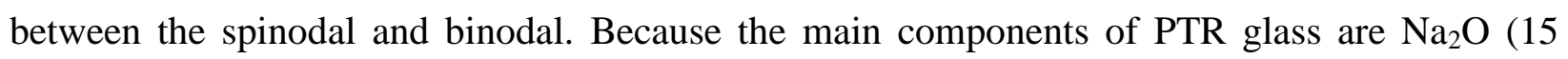
mol.\%) and $\mathrm{SiO}_{2}(70 \mathrm{~mol} . \%)$, enrichment of the matrix glass by sodium and fluorine was caused by formation of the droplet phase enriched by silicon oxide. However, on the basis of DSC data [102], it is clear that LLPS also occurs at a much lower temperature, but the extent of this effect is still unclear. It is therefore possible to generate a first scheme showing the temperature dependence of several processes happening in PTR glasses (Figure 9).

- Between approximately 250 and $>520{ }^{\circ} \mathrm{C}$ (after UV exposure), nucleation and growth of $\mathrm{Ag}$ and $\mathrm{AgBr}$ clusters occur [98].

- Between 430 and $560{ }^{\circ} \mathrm{C}$, nucleation of $\mathrm{NaF}$ occurs, and the maximum nucleation rate is achieved at approximately $485^{\circ} \mathrm{C}$. Treatment at this same temperature $\left(485^{\circ} \mathrm{C}\right)$ produces the lowest level of scattering in holographic optical elements recorded in PTR glass [68].

- Between 460 and $760{ }^{\circ} \mathrm{C}$, the $\mathrm{NaF}$ growth rate and $\mathrm{NaF}$ solubility monotonously increase until reaching $760^{\circ} \mathrm{C}$, a temperature above which no $\mathrm{NaF}$ crystal can be formed within the glass matrix.

- In parallel to these crystal nucleation and growth effects, liquid-liquid phase separation occurs. Below $760{ }^{\circ} \mathrm{C}$, it occurs in parallel to crystallization. This effect also exists at 
temperatures above the $\mathrm{NaF}$ solubility temperature and up to the binodal temperature of approximately $928^{\circ} \mathrm{C}$.

- Above the binodal temperature, no crystallization-related effects occur; therefore, this is the theoretical lowest temperature limit for glass melting or molding.

\section{Effects of PTR glass crystallization on microstructure and properties}

After studying the crystallization kinetics in PTR glass, we will now analyze in detail the microstructure of PTR glass after crystallization. The first point concerns the shape of the crystals in PTR glasses. NaF is known to have a cubic shape, which was confirmed in a study by Souza et al. [104]. Cuboidal crystals with micrometer size were observed by optical microscopy in PTR glass samples heat treated, for example, for 30 minutes at $650{ }^{\circ} \mathrm{C}$. However, it was demonstrated that extending such heat treatments for several hours at $650{ }^{\circ} \mathrm{C}$ results in dendritic growth of $\mathrm{NaF}$ crystals [109]. This crystal shape is the most commonly seen shape when studying crystals in (over-developed) PTR glasses using optical microscopy. The morphology of the dendrites (Figure 10) resembles that of "spikes" in the unexposed sample (a) and "snowflakes" in the UV-exposed sample (b). This outstanding morphological characteristic of PTR glass may result from the local chemical environment surrounding the crystals. The fine microstructure in the glass is very likely to be a form of liquid-liquid phase separation, as was presented in section 3, which appears to fade away near the dendrites. Another important feature shown in Figure 9 is a zone that was depleted of fine structures. This zone was referred to as being a courtyard, i.e., a ring surrounding the $\mathrm{NaF}$ crystals that was depleted in sodium and most of the fluorine. A very detailed study of this effect was presented in refs. [103,109]. It is worth noting that liquid phase separated glass regions also appear in the edges of the samples that lost 
fluorine during the thermal treatment. This effect was observed as a $40 \mu \mathrm{m}$ edge that has not crystallized but rather developed "liquid" phase droplets. This results correlated with the fluorine-depleted surface layer in hyper-developed PTR glass, detected using secondary ion mass spectrometry, and that was also reported in Lumeau et al. [62]. After thermal treatment, PTR glass structure consists of three different areas, i.e., a $\mathrm{NaF}$ crystal surrounded by a ring composed of $\mathrm{Na}^{+} \mathrm{F}^{-}$-depleted PTR glass within an unperturbed PTR glass, which was then discussed in several papers and used for explaining the origin of refractive index changes and some of the crystallization mechanisms in PTR glass. For example, Chamma et al. [110,111] studied the crystallization kinetics by X-ray diffraction. The evolution of the average crystal diameter in PTR glass nucleated for 100 minutes at $485{ }^{\circ} \mathrm{C}$, as a function of thermal treatment duration at $515{ }^{\circ} \mathrm{C}$, was analyzed (Table 4). As expected, the average $\mathrm{NaF}$ crystal diameter increases until reaching saturation. However, the apparent diameter reached $16 \mathrm{~nm}$ within the first hour and then saturated to approximately $20 \mathrm{~nm}$, corroborating the idea of growth in a continuously (NaF) depleted glass matrix. Regarding the volume fraction of crystals, it was shown to increase by 4 times when the heat treatment duration is increased from 1 to 72 hours at $515^{\circ} \mathrm{C}$. This represents the saturation of the crystalline volume fraction that can be formed in this glass at this temperature [102]. The average crystal diameter only increases by $20 \%$ during the same thermal treatment period. The increase of the crystalline volume fraction was explained by an increase in both the crystal number density and crystal size. This result showed that crystallization is a fast process at $515{ }^{\circ} \mathrm{C}$. The glass specimens were nucleated for 100 minutes at $485{ }^{\circ} \mathrm{C}$, which allowed abundant nucleation of the glass and, in turn, triggered fast growth of the crystals within the first hour of the thermal treatment. However, because of the limited amount of fluorine in the glass, the mentioned crystals cannot grow to diameters much larger than $20 \mathrm{~nm}$, and the increase 
of the volume fraction of $\mathrm{NaF}$ crystals is therefore explained by further nucleation and growth of $\mathrm{NaF}$ nanocrystals on these new sites.

Another important result was presented in that paper. Actually, XRD is normally an adequate method for qualitative study but not so much for the quantitative study of very small volume crystallized fractions. It is therefore worth questioning the validity of these kinetics because the $\mathrm{NaF}$ crystals tend to be too small and unstable to be observed by electron microscopy (and this explains why most of the studies used hyper-developments). To confirm the validity of the measured volume fraction and average crystal diameter, Rayleigh scattering theory was applied to calculate the expected scattering at $633 \mathrm{~nm}$ as a function of the measured crystal parameters. It was shown that the predicted optical scattering matches the measured scattering with an accuracy of $10 \%$. These results therefore confirm the validity of the parameters presented in Table 4 .

The cause of the NaF crystal size saturation at approximately $20 \mathrm{~nm}$ was also investigated. Chamma et al. [110,111] showed that heat-treated UV-exposed samples have dramatically different appearances depending on the temperature at which they were processed. Samples heat treated at $570{ }^{\circ} \mathrm{C}$ or below were translucent, whereas the samples heat treated at $590{ }^{\circ} \mathrm{C}$ and above were opaque and whitish. This difference of appearance is associated with significantly different levels of scattering, showing that the size of the created crystals is very different. This difference was not explained by a different volume fraction of crystals with full crystallization being achieved in each case. However, the average crystal diameter of samples heat treated at $600{ }^{\circ} \mathrm{C}$ was $30 \mathrm{~nm}$ (limited by the peak broadening due to the apparatus function), i.e., $50 \%$ larger than after the $550+{ }^{\circ} \mathrm{C}$ heat treatment. This difference of crystal size was associated with the intermediate region, which has the overall composition of PTR glasses but is depleted in fluorine. Because of this depletion, the glass has an increased glass transition 
temperature with a value expected to be similar to that of soda-lime silica (window) glasses, i.e., approximately $550{ }^{\circ} \mathrm{C}$. Then, when glasses are developed below the glass transition temperature of this intermediate glass, the growth of large NaF crystals is hampered, which explains the fast saturation of the crystal diameter to approximately $20 \mathrm{~nm}$. When this glass transition temperature is overcome, further $\mathrm{NaF}$ crystal growth and coarsening can occur, resulting in larger crystals and bulk scattering.

Up until now, we have indirectly analyzed the microstructure of PTR glass using either hyper-developments or indirect methods, such as XRD. However, Stookey [2] showed in his photochromic glasses a complex structure using electron microscopy. Instead of the expected cubic NaF crystals, a substantial number of silver crystals were observed with elongated pyramid shape. Such a shape is hard to see, however, in the current PTR glass because of the small crystal size and sensitivity of $\mathrm{NaF}$ crystals to e-beams of TEM, which tend to change the PTR glass microstructure because it provides enough energy to induce further NaF crystal growth and/or induce phase separation. Only recently has a study provided an opportunity to observe PTR glass microstructure using TEM [61,112]. After 1 hour at $515^{\circ} \mathrm{C}$, Glebova et al. [61,112] have shown crystals with similar shape as those determined by Stookey, i.e., NaF crystals with an elongated pyramid shape. The cubic crystals have a size of approximately $15 \mathrm{~nm}$ with attached tails $10 \mathrm{~nm}$ wide and $80 \mathrm{~nm}$ long. It is important to note that this size perfectly matches the crystal sizes reported by Chamma et al. [110,111] but also that traces of $\mathrm{AgF}$ and $\mathrm{NaBr}$ were detected, confirming the possible role of $\mathrm{Ag}$ and $\mathrm{Br}$ in the crystallization process.

It is therefore possible to summarize the PTR glass microstructure as in Figure 11. After thermal development, the glass shows three different regions:

- The first area is a cubic sodium fluoride crystal with an attached pyramidal tail (C). 
- As sodium and fluorine ions are consumed by the growing crystals, halos are formed with the same components as virgin PTR glass but depleted of sodium and almost exhausted of fluorine $(\mathrm{G} 1)$.

- The third area, far away from the crystals, is the unperturbed glass region with identical composition as virgin PTR glass (G2).

As was already presented, this particular crystal shape has a large impact on the final microstructure of PTR glass. In addition, it results in residual stresses as have been revealed in some publications $[111,113]$. It is well-known that internal residual stresses arise in all glassceramics upon cooling to room temperature from the crystallization temperature $[114,115]$. These stresses are due to the thermal expansion and the elastic mismatch between the crystalline and glassy phases. Therefore, the mechanical properties of glass-ceramics depend not only on their composition and microstructure but also on the type (tension or compression) and magnitude of these residual stresses. The thermal residual stresses generally have a significant impact on a material's mechanical performance, for example, its strength [116-118]. In the case of PTR glass, this effect was first revealed by Zwanziger et al. [113]. Using both the Selsing model [115] and solid-state nuclear magnetic resonance in combination with first principle calculations, the authors found that the crystals are under a huge tensile stress field of 610$800 \mathrm{MPa}$. For this stress level, the estimated critical crystal diameter for spontaneous cracking is approximately 1900-2300 nm, which greatly exceeds the observed diameters in PTR glasses (7$35 \mathrm{~nm}$ ) developed at $515-520{ }^{\circ} \mathrm{C}$. Hence, no spontaneous cracking is expected for the PTR glasses and indeed no cracking is observed. This stress level in crack-free PTRG glasses was then confirmed by Serbena et al. using XRD [114]. Large residual (tensile) stresses within the nanosize NaF crystals embedded in the glassy matrix of PTR glasses were demonstrated and 
estimated by studying the significant shift of the NaF X-ray diffraction lines to lower angles. The $\mathrm{NaF}$ crystals have cubic structure, and their volume fraction being quite small eliminates the overlap between the stress fields of neighboring crystals; hence, the stresses could be estimated and were shown to be very high, approximately $1 \mathrm{GPa}$. In addition, no cracking was observed. However, samples heat treated at higher temperature $\left(650^{\circ} \mathrm{C}\right)$ developed larger (micrometersized) crystals, revealing microcracking of the glassy matrix around the crystals, which partially relieved the residual stresses and decreased the shift of the XRD peaks [114]. The experimental results for the magnitude of the residual stresses and the critical crystal diameter for microcracking agreed with theoretical values calculated by the Selsing and the Davidge and Green models.

\section{Kinetics and origin of the refractive index change in PTR glass}

\subsection{Kinetics of the refractive index change in PTR glass}

One must now remember that the main application of PTR glass is in the fabrication of volume holographic optical elements. Although the term photosensitivity is relatively wide, i.e., the material properties can be changed by exposing the glass to light radiation. In optics, this generally refers to the ability to locally modify the local (bulk) refractive index of the glass by exposing certain parts to actinic radiation. In the case of PTR glass, the mechanisms are quite complex because they use two consecutive processes to induce the refractive index: exposure to UV radiation, which ionizes the glass, and a thermal treatment that induces $\mathrm{NaF}$ nanocrystals in the UV-exposed regions, which then leads to a localized refractive index change. Despite the maturity of PTR glass technology, the mechanisms that originate the local refractive index change are still unclear. Before analyzing in detail the refractive index change in PTR glass, it is 
interesting to understand parameters control this refractive index change. Lumeau et al. [71] showed that the refractive index change can be accurately predicted (with a precision better than $10 \%$ ) for any dosage of UV exposure (between 0 and $2 \mathrm{~J} / \mathrm{cm}^{2}$ ) and thermal treatment temperature (between 485 and $535{ }^{\circ} \mathrm{C}$ ) and duration (from a few minutes to a few hours depending on the temperature) using a basic physics model and Boltzmann laws. The two main key results are that the dependence of refraction $\Delta n(D, t, T)$ on dosage $(D)$ follows a hyperbolic dependence regardless of the thermal treatment temperature with this hyperbolic dependence being derived from basic photochemistry equations [119]:

$$
\Delta n(D, t, T)=\frac{\Delta n\left(E_{0}, t, T\right)\left(E_{0}+\varepsilon(t, T)\right) D}{E_{0}(D+\varepsilon(t, T))}
$$

Where $\varepsilon(t, T)$ is a thermodynamic parameter that needs to be determined for each thermal treatment temperature and duration, $E_{0}$ is a reference energy set to $0.9 \mathrm{~J} / \mathrm{cm}^{2}$, and $\Delta n\left(E_{0}, t, T\right)$ is another parameter that can be predicted using the JMAK theory [120-123]:

$$
\Delta n\left(E_{0}, t, T\right)=\Delta n_{\max }\left(E_{0}, T\right)\left(1-\exp \left(-K(T) t^{n}\right)\right)
$$

where $\Delta n_{\max }\left(E_{0}, T\right)$ is the refractive index at saturation, $K(T)$ is a parameter describing the slope of refractive index change dependence on temperature at $t=0$, and $n$ is the equivalent of an Avrami coefficient describing the type of crystallization. A key result is that the coefficient is $1.5 \pm 0.2$. The coefficient $n$ is a parameter describing the crystallization mechanism. When it equals approximately 1.5, it can be associated [121-123], from the point of view of crystallization, with diffusion-controlled growth of two-dimensional (discs or lath-shaped) particles from pre-existing nuclei. However, the NaF crystals are expected to grow isotropically with a cubic shape, which is not the situation predicted by $n=1.5$. However, Chamma et al. $[110,111]$ have shown that this dependence is not so straight forward because the refractive index change is not strictly 
proportional to the volume fraction of $\mathrm{NaF}$ crystals. Additional studies have also shown that the refractive index change achieved in homogeneously exposed PTR glass also depends on the annealing process and the cooling rate performed at the end of the thermal treatment schedule [101]. It is therefore obvious that a thorough study of the different mechanisms that can lead to the experimentally observed refractive index change in PTR glass is still necessary. In the following section, we will discuss the origin of the refractive index change in homogeneously exposed PTR glass.

\subsection{Mechanisms of the refractive index change in homogeneously exposed PTR glass}

The origin of localized refractive index changes in uniformly UV-exposed PTR glass was studied in detail by Lumeau et al. [72] a few years ago. Before reviewing the different possible mechanisms that might originate such a refractive index change, it is important to remember that the precipitation of sodium fluoride crystals correlates with the beginning of the refractive index decrease in the UV-exposed regions of the glass. It must be stressed that a (smaller) change in the refractive index also occurs in the unexposed areas [124,125]. However, as the main application of PTR glass is for the recording volume Bragg gratings, the important parameter is

the refractive index difference between the UV-exposed area $\left(n^{U V \text {-exposed }}\right)$ and the unexposed area $\left(n^{\text {unexposed }}\right)$ :

$$
\Delta n=n^{\mathrm{UV}-\mathrm{exposed}}-n^{\mathrm{unexposer}}
$$

It has been found $[4,126]$ that the overall refractive index change is negative $(\Delta n<0)$; therefore, PTR glass is a negative photosensitive medium. Using a similar PTR glass microstructure model 
in Figure 11, the authors of ref. [72] tried to access all possible sources of refractive index changes and write a simple phenomenological equation to account for these contributions:

$$
\begin{aligned}
\Delta n^{\text {exp }}= & {\left[\Delta n^{\text {Crystalline }} V^{\mathrm{NaF}}+\Delta n^{\text {Vitreous }} V^{\mathrm{G} 1}\right] } \\
& +\left[\Delta n^{\mathrm{V}, \mathrm{Gl}} V^{\mathrm{G} 1}+\Delta n^{\mathrm{V}, \mathrm{G} 2} V^{\mathrm{G} 2}\right] \\
& +\left[\Delta n^{\text {Stress } 1} V^{\mathrm{NaF}}+\Delta n^{\text {Stress2 }} V^{\mathrm{G} 1}+\Delta n^{\mathrm{Stres} 3} V^{\mathrm{G} 2}\right]
\end{aligned}
$$

By supposing that there is no significant crystallization in the unexposed areas, the refractive index in those areas would change only due to variations of cooling regimes:

$$
\Delta n^{\text {unexp }}=\Delta n^{\mathrm{v}} \times V^{\mathrm{G} 2}
$$

Each contribution in equations (8) and (9) is a product (or integration) between the refractive index change $\left(\Delta n^{i}\right)$ due to each effect and the volume fraction $\left(V^{i}\right)$ of the region contributing to that particular effect. $V^{N a F}$ is the volume fraction of crystals, which is typically between 0.1 and $3 \%, V^{G l}$ is the volume fraction of glass that has been depleted in sodium and fluorine, and $V^{G 2}$ is the volume fraction of glass that has not been perturbed and, therefore, has the same composition as regular PTR glass.

The amplitude of each of these contributions was analyzed and estimated on the basis of further experiments that will not be detailed in this paper. We will restrict our presentation to the basic results that were obtained in that study. Regarding the refractive index change appearing after thermal treatment in the UV-exposed areas, the first term within brackets represents the direct contribution of crystallization to the refractive index change. The appearance of sodium fluoride crystals induces a refractive index change $\left(\Delta n^{\text {crystalline }}\right)$ due to their lower refractive index (n equals approximately 1.3) compared to the refractive index of the original glass matrix ( $\mathrm{n}$ equal approximately 1.5). Furthermore, this effect is accompanied by $\mathrm{NaF}$ depletion of the surrounding glass, which in turn changes the refractive index of the glass matrix $\left(\Delta n^{\text {vitreous }}\right)$. 
However, the authors showed that the atomic refractions of sodium and fluorine are close in the crystalline and vitreous phases, such as the large local decrease of refractive index change due to $\mathrm{NaF}$ crystal formation is compensated for by a much smaller refractive index increase of the much larger volume of the $\mathrm{Na}^{+} \mathrm{F}^{-}$-depleted PTR glass layer. The terms within the second bracket, $\Delta n^{V, G 1}$ and $\Delta n^{V, G 2}$, refer to changes of refractive index in the $\mathrm{Na}^{+} \mathrm{F}^{-}$-depleted and unperturbed PTR glass, respectively, due to the change in specific volume that occurs during cooling of PTR glass (after crystallization treatment) in comparison with the specific volume of the virgin glass, which underwent fine annealing. This second term was shown to be independent of the presence of $\mathrm{NaF}$ crystals and is not therefore compensated by the change of specific volume during cooling from the crystallization temperature to room temperature, which would contribute to the refractive index change in the unexposed part. The third and last term represents the stresses that appear in the NaF crystals, surrounding glass and unperturbed glass. Crystallization is typically performed at approximately $515^{\circ} \mathrm{C}$. PTR "glass" is a viscous liquid at this temperature because $T_{g}$ is approximately $460{ }^{\circ} \mathrm{C}$, and therefore, stresses caused by structural transformations quickly relax. However, when the material is cooled from $T_{g}$ to approximately $25^{\circ} \mathrm{C}$, stresses appear in the elastic medium (glass).As already presented in the previous section, the coefficient of thermal expansion (CTE, $\alpha$ ) of silicate glasses increases with an increase of fluorine content [127]. Hence, we have

$$
\alpha_{\text {PTR wo NaF }}<\alpha_{\text {PTR w NaF }}<\alpha_{\mathrm{NaF}}
$$

The coefficient of thermal expansion (CTE) of regular PTR glass is approximately $10 \times 10^{-}$ ${ }^{6} \mathrm{~K}^{-1}$, whereas that of the cubic $\mathrm{NaF}$ crystals is approximately $36 \times 10^{-6} \mathrm{~K}^{-1}$, i.e., almost 4 times higher than the glass CTE. Hence, after crystallization and cooling to room temperature, "hydrostatic" radial and tangential stresses appear within the $\mathrm{NaF}$ crystals and induce a refractive 
index change on them $\left(\Delta \mathrm{n}^{\text {stress } 1}\right)$ [116]; radial and tangential stresses change the refractive index of the surrounding glass $\left(\Delta \mathrm{n}^{\text {stress2 }}\right)$ [116], and finally, there will be some stresses between the depleted and unperturbed glass $\left(\Delta \mathrm{n}^{\text {stress3 }}\right)$. The spatial distribution of these stresses is not uniform. The stresses inside the NaF crystals are constant, whereas the stresses in the depleted and nondepleted $\mathrm{Na}$ and $\mathrm{F}$ regions decay with distance, $\mathrm{r}^{-3}$. Moreover, because of the much larger difference in thermal expansion coefficients, the main contribution is expected to be the stresses at the interface between the $\mathrm{NaF}$ crystals and the surrounding (fluorine and sodium) depleted glass. The total contribution of each type of stress to the refractive index change is a volume integral across the areas occupied by these stresses. In ref. [113], first estimations showed that stresses should contribute to the refractive index change within the order of $-0.08 \%$, i.e., within the order of magnitude of what is commonly observed in PTR glass.

Additional results tended to confirm the role of stress in the refractive index change in PTR glass. The first is that stresses, as measured by high-temperature XRD, disappear when the temperature is increased up to the thermal development temperature. However, high-temperature interferometric measurements confirmed that the refractive index change is canceled when the temperature is increased up to the temperature that was used to induce the refractive index change. Lumeau et al. [72] therefore concluded that the high residual stress field that surrounds the NaF crystals is the most important cause of the photo-thermo-induced refractive index change in PTR glass.

These data were recently reinvestigated by measuring the refractive index change at low and high temperatures and continuously monitoring the refractive index change during the heating and cooling processes $[72,128]$. Such an experiment is tricky because of the thermal instability of the interferometric method. However, although a quantitative analysis could not be 
carried out, i.e., the exact dependence of the refractive index change on temperature, qualitative dependence could be extracted. It was shown that the refractive index change is constant below the glass transition temperature, $T_{g}$, and only decreases at higher temperatures, becoming close to zero at the development temperature. In addition, as expected, the stresses monotonously decreased with the temperature from room temperature up to the final thermal treatment temperature that was used to induce the refractive index change [72]. This result, therefore, proves that the preliminary conclusions of ref. [72], although very attractive, are inaccurate and that stress, if contributing to the refractive index change in PTR glass, has a more complex role.

At this stage of this analysis, it is important to emphasize that after UV exposure and thermal treatment, the PTR glass nanostructure has three phases. As a result, there is a significant part of the residual glass that is depleted of $\mathrm{Na}^{+}$and $\mathrm{F}^{-}$. Furthermore, contrary to what was presented in ref. [72], $\Delta n^{V, G 1}$ and $\Delta n^{V, G 2}$, which refer to changes of refractive index in the $\mathrm{Na}^{+} \mathrm{F}^{-}$-depleted and unperturbed PTR glass, respectively, are not strictly identical due to the change of specific volume that occurs during cooling of PTR glass (after crystallization treatment) in comparison with the specific volume of the virgin glass, which underwent fine annealing. It is well-known that the glass transition temperature of a glass is strongly influenced by the glass composition. Fluorine is known to deeply impact $T_{g}$ by changing it by several degrees per wt.\%. PTR glass is a silicate glass with a glass transition temperature of approximately $460{ }^{\circ} \mathrm{C}$. Its composition allows for assessing that the glass transition of the same PTR glass without fluorine would lie between 550 and $580{ }^{\circ} \mathrm{C}$. In other words, when developing PTR glass at $515^{\circ} \mathrm{C}$, the $\mathrm{Na}^{+} \mathrm{F}^{-}$-depleted zones surrounding the $\mathrm{NaF}$ crystals change their state from a supercooled liquid to a glass because the heat-treatment temperature becomes lower than their $T_{g}$ ! Upon cooling, it is obvious that this 
phase change will have a deep impact on the properties. Before describing these effects further, let us remember some basic physical properties of glasses around $T_{g}$. For example, the coefficient of thermal expansion of a glass is almost constant as a function of temperature but increases typically 3 times when the temperature is increased above $T_{g}$. For the same reasons, the dependence of the specific volume or its density on temperature also have different paths and slopes whether the glass is above or below the glass transition temperature [50]. Figure 12 provides an illustration of what occurs in the glass during cooling [128].

- Between the development temperature $\left(515^{\circ} \mathrm{C}\right)$ and the $T_{g}$ of unperturbed PTR glass $\left(460{ }^{\circ} \mathrm{C}\right.$ ), the change in the specific volume of the $\mathrm{Na}^{+} \mathrm{F}^{-}$-depleted glass and the unperturbed glass follow different paths. Therefore, first of all, the overall average density of the UV-exposed glass becomes different from that of the unexposed glass, resulting in a temperature-dependent refractive index change. In addition, the difference in the coefficient of thermal expansion between these two zones can also result in stresses that might further contribute to a change in the refractive index.

- Below the $T_{g}$ of unperturbed PTR glass $\left(460{ }^{\circ} \mathrm{C}\right)$ and down to room temperature, both $\mathrm{Na}^{+} \mathrm{F}^{-}$-depleted glass and unperturbed glass follow similar paths because of the low effect of $\mathrm{F}$ on the physical properties. This explains why the refractive index change is constant below $T_{g}$.

While this new mechanism is at this date the one that appears to be the most accurately describing experimental data that have been acquired, it still remains not completely validated and would require further investigations.

\section{Conclusions}


In this article, we present an overview of the (so far known) photo-thermo-refraction and crystallization processes occurring in photo-thermo-refractive glass. We show that, after almost seven decades since its invention, the intricate details of the mechanisms of photo-thermorefraction and crystallization pathways that produce localized changes of the refractive index in PTR glass are only partially known.

Despite the lack of full knowledge, today's technology allows for melting of PTR glasses with absorption in the near IR region of $5 \times 10^{-5} \mathrm{~cm}^{-1}$, refractive index fluctuations (homogeneity) of only $10^{-5}$ (before crystallization) and apertures up to $100 \times 100 \mathrm{~mm}^{2}$. After crystallization, these partially crystalline glasses are commercially used for the fabrication of volume Bragg gratings. PTR glasses with diffraction efficiency up to $99.9 \%$, absorption in near IR of $1-2 \times 10^{-4} \mathrm{~cm}^{-1}$, scattering down to $5 \times 10^{-3} \mathrm{~cm}^{-1}$ and aperture up to $50 \times 50 \mathrm{~mm}^{2}$ are integrated in various laser systems with energies exceeding $10 \mathrm{~kW}(\mathrm{CW})$. At least three companies commercialize volume Bragg gratings made of PTR glass. However, further improvement in terms of higher efficiency with lower scattering and absorption losses will critically depend on future scientific understanding of the complex photo-thermo-refractive processes and warrants further research. 


\section{References:}

[1] S.D. Stookey, "Photosensitive glass (a new photographic medium)", Industrial and Engineering Chemistry 41, 856 (1949).

[2] S.D. Stookey, G.H. Beall, J.E. Pierson, "Full-color photosensitive glass", Journal of Applied Physics 49, 5114 (1978).

[3] N.F. Borrelli, D.L. Morse, P.A. Sachenik, "Integral photosensitive optical device and method", US Patent 4, 541, 053 (1985).

[4] V.A. Borgman, L.B. Glebov, N.V. Nikonorov, G.T. Petrovskii, V.V. Savvin, A.D.Tsvetkov, "Photothermal refractive effect in silicate glasses", Soviet Physics. Doklady 34, 1011-1013 (1989).

[5] L.B. Glebov, N.V. Nikonorov, E.I. Panysheva, G.T. Petrovskii, V.V. Savvin, I.V.

Tunimanova, V.A. Tsekhomsky, "Polychromatic glasses - a new material for recording volume phase holograms", Soviet Physics. Doklady. 35, 878 (1990).

[6] O.M. Efimov, L.B. Glebov, L.N. Glebova, K.C. Richardson, V.I. Smirnov, "High efficiency Bragg gratings in photo-thermo-refractive glass", Applied Optics 38, 619-627(1999).

[7] O.M. Efimov, L. B. Glebov, L. N. Glebova, V. I. Smirnov, "Process for production of high efficiency volume diffractive elements in photo-thermo refractive glass", United States Patent 6, 586, 141 B1. July 1, 2003.

[8] O. M. Efimov, L. B. Glebov, V. I. Smirnov, "High efficiency volume diffractive elements in photo-thermo-refractive glass", United States Patent 6,673,497, January 6, 2004.

[9] J. Lumeau, L. Glebova and L. B. Glebov, "Near-IR absorption in high purity photo-thermorefractive glass and holographic optical elements: measurement and application for high energy lasers", Applied Optics 50(30), 5905-5911 (2011). 
[10] www.OptiGrate.com

[11] www.ondax.com

[12] www.pd-ld.com

[13] I. Ciapurin, L. Glebov, and V. Smirnov, "Modeling of phase volume diffractive gratings, part 1: Transmitting sinusoidal uniform gratings", Optical Engineering 45, 015802(2006).

[14] L. Siiman, J. Lumeau, L. Canioni and L.B. Glebov, "Ultrashort laser pulse diffraction by volume Bragg gratings in PTR glass", Optics Letters 34(17), 2572-2574 (2009).

[15] I. Ciapurin, D. Drachenberg, V. Smirnov, G. Venus, and L. Glebov, "Modeling of phase volume diffractive gratings, part 2: Reflecting sinusoidal uniform gratings, Bragg mirrors", Optical Engineering 51, 058001 (2012).

[16]V. Smirnov, J. Lumeau, S. Mokhov, B. Ya. Zeldovich and L. B. Glebov, "Ultra-narrow bandwidth Moiré reflecting Bragg gratings recorded in photo-thermo-refractive glass", Optics Letters 35(4), 592-594 (2010).

[17] L. B. Glebov, E. Flecher, V. I. Smirnov, A. Galvanauskas, K. Liao, "Stretching and compression of laser pulses by means of high efficiency volume diffractive gratings with variable periods in photo-thermo-refractive glass," United States Patent 7,424,185 B2 (2008). [18] O. Andrusyak, L. Canioni, I. Cohanoschi, E. Rotari, V. Smirnov, G. Venus, L. Glebov, "Cross-correlation technique for dispersion characterization of chirped volume Bragg gratings", Applied Optics, 48 (30), pp. 5786-5792 (2009).

[19] L. Siiman, J. Lumeau, L. B. Glebov, "Phase Fresnel lens recorded in PTR glass by selective exposure to IR ultrashort laser pulses", Optics Letters34(1), 40-42 (2009).

[20] M. SeGall, V. Rotar, J. Lumeau, S. Mokhov, B. Ya. Zeldovich and L. B. Glebov, "Binary volume phase masks in photo-thermo-refractive glass", Optics Letters 37(7), 1190-1192 (2012). 
[21] P. Hofmann, R. Amezcua Correa, E. Antonio-Lopez, D. Ott, M. SeGall, I. Divliansky, J. Lumeau, L. Glebova, L. Glebov, N. Peyghambarian, and A. Schulzgen, "Strong Bragg gratings with $42 \mathrm{pm}$ bandwidth in optical fiber made of highly photosensitive photo-thermo-refractiveglass", IEEE Photonics Technology Letters 25(1), 25-28 (2013).

[22] L. Glebov, "Volume Bragg gratings in PTR glass—-new optical elements for laser design", 3rd Advanced Solid-State Photonics (ASSP) Topical Meeting. ASSP Technical Digest, Paper Code MD1, Nara, Japan, January 2008.

[23] L. Glebov, "High brightness laser design based on volume Bragg gratings", Laser Source and System Technology for Defense and Security II, Proceedings of SPIE 6216, 621601 (2006). [24] N. Nikonorov, V. Aseev, V. Dubrovin, A. Ignatiev, S. Ivanov, Y. Sgibnev, and A. Sidorov, "Design and Fabrication of Optical Devices based on New Polyfunctional Photo-thermorefractive Glasses", Proceedings of the 4th International Conference on Photonics, Optics and Laser Technology, 18-25, Rome, Italy (2016).

[25] X. Zhang, X. Yuan, J. Feng, F. Gao, B. Xiong, K. Zou, "Optimization of spatial filter with volume Bragg gratings in photo-thermo-refractive glass", Optics Letters, 39 (3), 663-665 (2014). [26] B. Anderson, G. Venus, D. Ott, I. Divliansky, and L. B. Glebov, "Transverse mode selection in solid state resonators by way of volume Bragg gratings," in Frontiers in Optics 2013, P. Delyett, Jr. and D. Gauthier, eds., OSA Technical Digest (Optical Society of America, 2013), paper LTh4F.3.

[27] D. Pabœuf, D. Vijayakumar, O. Bjarlin Jensen, B. Thestrup, J. Lim, S. Sujecki, E. Larkins, G. Lucas-Leclin, and P. Georges, "Volume Bragg grating external cavities for the passive phase locking of high-brightness diode laser arrays: theoretical and experimental study," J. Opt. Soc. Am. B 28, 1289-1299 (2011). 
[28] A. Glebov, O. Mokhun, V. Smirnov, L. Glebov, A. Rapaport, B. Roussel, H.-J. Reich, and F. Adar, "Novel volume Bragg grating notch filters for ultralow-frequency Raman measurements", The 3rd Scientific EOS Annual Meeting (EOSAM 2010), paper 4007. [29] N. Vorobiev, L. Glebov, and V. Smirnov, "Single-frequency-mode Q-switched Nd:YAG and Er:glass lasers controlled by volume Bragg gratings", Opt. Express 16, 9199-9204 (2008). [30] A. Gourevitch, G. Venus, V. Smirnov, D.A. Hostutler, and L. Glebov "Continuous wave, 30 W laser-diode bar with $10 \mathrm{GHz}$ linewidth for Rb laser pumping" Opt. Lett. 33, 702-704 (2008). [31] O. Andrusyak, V. Smirnov, G. Venus, L. Glebov, "Beam combining of lasers with high spectral density using volume Bragg gratings"', Optics Communications 282 (13), 2560-2563 (2009).

[32] D. Ott, I. Divliansky, B. Anderson, G. Venus, L. Glebov, "Scaling the spectral beam combining channels in a multiplexed volume Bragg grating", Optics Express 21 (24), 2962029627 (2013).

[33] D. R. Drachenberg, O. Andrusyak, G. Venus, V. Smirnov, J. Lumeau, L. Glebov, "Ultimate efficiency of spectral beam combining by volume Bragg gratings", Applied Optics 52 (30), 7233-7242 (2013).

[34] S. Yin, B. Zhang, "Analysis of the output characteristics of high-power fiber lasers after spectral beam combination", Guangxue Xuebao/Acta Optica Sinica 31 (2), 0214002 (2011). [35] K.-H. Liao, M.-Y. Cheng, E. Flecher, V.I. Smirnov, L. Glebov, and A. Galvanauskas, "Large-aperture chirped volume Bragg grating based fiber CPA system", Opt. Express 15, 48764882 (2007). 
[36] L. Glebov, V. Smirnov, E. Rotari, I. Cohanoschi, L. Glebova, O. Smolski, J. Lumeau, C. Lantigua, A. Glebov, "Volume chirped Bragg gratings - monolithic components for stretching and compression of ultrashort laser pulses", Optical Engineering 53(5), 051514 (2014).

[37] V. A. Aseev and N. V. Nikonorov, "Spectroluminescence properties of photothermorefractive nanoglass-ceramics doped with ytterbium and erbium ions," J. Opt. Technol. 75, 676-681 (2008).

[38] L. Glebova, J. Lumeau and L. B. Glebov, "Photo-thermo-refractive glass co-doped with Nd3+ as a new laser medium", Optical Materials33, 1970-1974 (2011).

[39] Y. Sato, T. Taira, V. Smirnov, L. Glebova, and L. Glebov, "Continuous-wave diodepumped laser action of Nd3+-doped photo-thermo-refractive glass," Opt. Lett. 36, 2257-2259 (2011).

[40]A. Ryasnyanskiy, N. Vorobiev, V. Smirnov, J. Lumeau, L. Glebova, O. Mokhun, Ch. Spiegelberg, M. Krainak, A. Glebov and L. Glebov, "DBR and DFB lasers in Nd and Yb doped photo-thermo-refractive glasses", Optics Letters 39(7), 2156-2159 (2014).

[41] Y. Sgibnev, N. Nikonorov, A. Ignatiev, V. Vasilyev, and M. Sorokina, "Photostructurable photo-thermo-refractive glass," Opt. Express 24, 4563-4572 (2016).

[42] Y. M. Sgibnev ,N. V. Nikonorov, V. N. Vasilev, A. I. Ignatiev, "Optical gradient waveguides in photo-thermo-refractive glass formed by ion exchange method", Journal of Lightwave Technology 33 (17), 3730-3735 (2015).

[43] http://dilas.com/products/search

[44] L.B. Glebov, "Photosensitive glass for phase hologram recording," Glastech. Ber. Glass Sci. Technol., 71C, 85-90 (1998). 
[45] L.B. Glebov, "Photochromic and photo-thermo-refractive (PTR) glasses," In Encyclopedia of Smart Materials, Volume 2. John Wiley \& Sons, NY, 770-780 (2002).

[46] L. Glebov, "Fluorinated silicate glass for conventional and holographic optical elements," Window and Dome Technologies and Materials X, edited by Randal W. Tustison, Proc. of SPIE 6545, 654507 (2007).

[47] L. B. Glebov, "Photosensitive holographic glass - new approach to creation of high power lasers," Phys. Chem. Glasses: Eur. J. Glass Sci. Technol. B, 48, 123-128 (2007).

[48] J.S. Stroud, "Photoionization of Ce3+ in glass," J. Chem. Phys. 35, 844-850 (1961).

[49] A. V. Dotsenko, L. B. Glebov, V. A. Tsechomsky, "Physics and Chemistry of Photochromic Glasses", CRC Press (1998).

[50] J. E. Shelby, "Introduction to Glass Science and Technology," Rcs Paperbacks Series (2005).

[51] E. I. Panysheva, I. V. Tunimanova, V. A. Tsekhomskii, "The Role of Tin and Antimony in the Coloring of Polychromatic Glass," Fiz. Khim. Stekla 16 (3), 417-423 (1990).

[52] P. Wang, M. Lu, W. Li, F. Gao, B.Peng, "Crystallization and absorption properties of novel photo-thermal refractive glasses with the addition of B2O3", Journal of Non-Crystalline Solids 368 (1), 55-62 (2013).

[53] V. D. Dubrovin, A. I. Ignatiev, and N. V. Nikonorov, "Chloride photo-thermo-refractive glasses", Opt. Mater. Express 6, 1701-1713 (2016).

[54] A.I. Ignat'Ev, N. V. Nikonorov, A. I. Sidorov, T. A. Shakhverdov, "Influence of UV irradiation and heat treatment on the luminescence of molecular silver clusters in photo-thermorefractive glasses", Optics and Spectroscopy (English translation of Optika i Spektroskopiya), 114 (5), 769-774 (2013). 
[55] S. A. Ivanov, A. I. Ignatiev, N. V. Nikonorov, V. A. Aseev, "Characteristics of PTR glass with novel modified composition", Radiophysics and Quantum Electronics 57.8-9, 659-664 (2015).

[56] C. Bocker, C. Rüssel, "Self-organized nano-crystallisation of BaF2 from $\mathrm{Na} 2 \mathrm{O} / \mathrm{K} 2 \mathrm{O} / \mathrm{BaF} 2 / \mathrm{Al} 2 \mathrm{O} 3 / \mathrm{SiO} 2$ glasses", Journal of the European Ceramic Society 29, 12211225 (2009).

[57] C. Russel, "Nanocrystallization of $\mathrm{CaF} 2$ from $\mathrm{Na} 2 \mathrm{O} / \mathrm{K} 2 \mathrm{O} / \mathrm{CaO} / \mathrm{CaF} 2 / \mathrm{Al} 2 \mathrm{O} 3 / \mathrm{SiO} 2$ ", Glasses Chem. Mater. 17, 5843-5847 (2005).

[58] R. Petrini Fogaca de Almeida, C. Bocker, and C. Russel, "Size of CaF2 crystals precipitated from glasses in the $\mathrm{Na} 2 \mathrm{O} / \mathrm{K} 2 \mathrm{O} / \mathrm{CaO} / \mathrm{CaF} / \mathrm{A} 12 \mathrm{O} 3 / \mathrm{SiO} 2$ system and percolation theory", Chem. Mater. 20, 5916-5921 (2008).

[59] M. Stoica, A. Herrmann, J. Hein, C. Rüssel, "UV-vis spectroscopic studies of CaF2 photothermo-refractive glass," Optical Materials 62, 424-432 (2016).

[60] M. Klimov, L. Glebova and L. B. Glebov, "Determination of composition of photo-thermorefractive glass by SIMS", Physics and Chemistry of Glasses - European Journal of Glass Science and Technology Part B 48(5), 313-316 (2007).

[61] M. Klimov, L. Glebov, L. Glebova, "Differentiation of crystalline and amorphous phases in photothermorefractive glass by secondary ion mass spectrometry", Journal of Vacuum Science \& Technology B 34, $03 \mathrm{H} 118$ (2016).

[62] J. Lumeau, A. Sinitskiy, L. N. Glebova, L. B. Glebov and E. D. Zanotto, "Method to assess the homogeneity of photosensitive glasses: application to photo-thermo-refractive glass", Journal of Non Crystalline Solids 355, 1760-1768 (2009). 
[63] Y. Sgibnev, N. Nikonorov, A. Ignatiev, V. Vasilyev, and M. Sorokina, "Photostructurable photo-thermo-refractive glass," Opt. Express 24, 4563-4572 (2016).

[64] C. A. Lantigua, "Metrology of volume chirped Bragg gratings recorded in photo-thermorefractive glass for ultrashort pulse stretching and compressing", Master of Science thesis, Figure 32, (2013).

[65] M. Anne, J. Lumeau, L. Glebova and L.B. Glebov, "Specific absorption spectra of cerium in multicomponent silicate glasses", Journal of Non Crystalline Solids 356 (44-49), 2337-2343 (2010).

[66] J. Lumeau, L. Glebova and L. B. Glebov, "Influence of UV-exposure on the crystallization and optical properties of photo-thermo-refractive glass", Journal of Non Crystalline Solids 354, 425-430 (2008).

[67] J. Lumeau, and L. Glebov, "Mechanisms and kinetics of short pulse laser-induced destruction of silver containing nano-particles in multicomponent silicate photo-thermorefractive glass", Applied Optics 53(31), 7362-7368 (2014).

[68] J. Lumeau, L. Glebova, L. Glebov, "Absorption and scattering in photo-thermo-refractive glass induced by UV exposure and thermal development", Optical Materials 36, 621-627 (2014). [69] V.D. Dubrovin, A.I. Ignatiev, N.V. Nikonorov, A.I. Sidorov, T.A. Shakhverdov, D.S. Agafonova, "Luminescence of silver molecular clusters in photo-thermo-refractive glasses", Optical Materials 36 (4), 753-759 (2014).

[70] T. Cardinal , O. M. Efimov, H. G. François-Saint-Cyr, L. B. Glebov, L. N. Glebova, V. I. Smirnov, "Comparative study of photo-induced variations of X-ray diffraction and refractive index in photo-thermo-refractive glass", Journal of Non-Crystalline Solids 325 (1-3), 275-281 (2003). 
[71] J. Lumeau and L. B. Glebov, "Modeling of the induced refractive index kinetics in photothermo-refractive glass", Optical Materials Express 3(1), 95-104 (2013).

[72] J. Lumeau, L. Glebova, L. B. Glebov, V. Golubkov and E. D. Zanotto, "Origin of crystallization-induced refractive index changes in photo-thermo-refractive glass", Optical Materials 32, 139-146 (2009).

[73] V.S. Vishnu, G. George, V. Divya, M.L.P. Reddy, "Synthesis and characterization of new environmentally benign tantalum-doped $\mathrm{Ce} 0.8 \mathrm{Zr} 0.2 \mathrm{O} 2$ yellow pigments: Applications in coloring of plastics", Dyes and Pigments, 82(1) 53-57 (2009).

[74] S.Y. Marzouk, F.M. Ezz-Eldin, "Optical study of Ce3+ ion in gamma-irradiated binary barium-borate glasses", Physica B 430, 3307-3315 (2008).

[75] E.N. Boulos, L.B. Glebov, "Absorption of iron and water in the $\mathrm{Na} 2 \mathrm{O}-\mathrm{CaO}-\mathrm{MgO}-\mathrm{SiO} 2$ glasses. I. Separation of ferrous and hydroxyl spectra in the near IR region", J. Non-Cryst. Solids 221, 213 (1997).

[76] L.B. Glebov, E.N. Boulos, "Absorption of iron and water in the Na2O-CaO-MgO-SiO2 glasses II. Selection of intrinsic, ferric, and ferrous spectra in the visible and UV regions", J. Non-Cryst. Solids 424, 49-62 (1998).

[77] A. M. Efimov, N. V. Nikonorov, A. I. Ignatiev, and E. S. Postnikov, "Quantitative UV-VIS spectroscopic studies of photo-thermo-refractive glasses. II. Manifestations of Ce3+ and Ce(IV) valence states in the UV absorption spectrum of cerium-doped photo-thermo-refractive matrix glasses", J. Non-Cryst. Solids 361, 26-37 (2013).

[78] A. M. Efimov, A. I. Ignatev, N. V. Nikonorov, and E. S. Postnikov, "Spectral components that form UV absorption spectrum of $\mathrm{Ce} 3+$ and $\mathrm{Ce}(\mathrm{IV})$ valence states in matrix of photothermorefractive glasses," Opt. Spectrosc. 111(3), 426-433 (2011). 
[79] A.M. Efimov, A.I. Ignatiev, N.V., Nikonorov, E.S. Postnikov, "Photo-thermo-refractive glasses: Effects of dopants on their ultraviolet absorption spectra", International Journal of Applied Glass Science 6 (2), 109-127 (2015).

[80] J. Lumeau, L. Glebova, and L. B. Glebov, "Photo-thermo-induced absorption in photothermo-refractive glass", Glass and Optical material division, Spring 2012 Meeting (Saint Louis, Missouri, USA), invited talk, paper GOMD-SII-034-2012, May 2012.

[81] L. Glebov, V. Dokuchaev, M. Petrov, G. Petrovskii, "Absorption spectra of color centers in alkali silicate glasses", Sov. J. Glass Phys. Chem. 16, 31 (1990).

[82] K. Chamma, J. Lumeau, L. Glebova, and L. B. Glebov, "Generation and bleaching of intrinsic color centers in photo-thermo-refractive glass matrix", Journal of Non Crystalline Solids 356 (44-49), 2363-2368 (2010).

[83] K. Chamma, J. Lumeau, L. Glebova, L. Glebov, "Study of ionization of cerium in multicomponent silicate glasses", Glass and Optical material division, Spring 2010 Meeting (Corning, New-York, USA), paper GOMD-SV-031-2010, May 2010.

[84] A. M. Efimov, A. I. Ignatiev, N. V. Nikonorov, E. S. Postnikov, "Quantitative UV-VIS spectroscopic studies of photo-thermo-refractive glasses. I. Intrinsic, bromine-related, and impurity-related UV absorption in photo-thermo-refractive glass matrices", Journal of NonCrystalline Solids 357, Issues 19-20, 3500-3512 (2011).

[85] N.V. Nikonorov, Sidorov A.I. and Tsekhomskii V.A., Chapter 10: Silver nanoparticles in oxide glasses: technologies and properties, in Nanotechnology and Nanomaterials, "Silver Nanoparticles", book edited by David Pozo Perez, ISBN 978-953-307-028-5, Published: March $1,2010$. 
[86] C. J. Magon, J. P. Donoso Gonzalez, J. F. Lima, and H. Eckert, E. D. Zanotto, J. Lumeau, L. Glebova, L. B. Glebov, "Electron Paramagnetic Resonance (EPR) studies on the photo-thermo ionization process of photo-thermo-refractive glasses", submitted to Journal of Non-Crystalline Solids (2016).

[87] L. Siiman, J. Lumeau, and L. B. Glebov, "Nonlinear photosensitivity of photo-thermorefractive glass by high intensity laser irradiation", Journal of Non Crystalline Solids, 354, 40704074 (2008).

[88] L. Siiman, J. Lumeau, L. B. Glebov, "Nonlinear photoionization and laser-induced damage in silicate glasses by infrared ultrashort laser pulses", Applied Physics B 96(1), 127-134 (2009). [89] D. A. Klyukin, V. D. Dubrovin, A. S. Pshenova, S. E. Putilin, T. A. Shakhverdov, A. N. Tsypkin, A. I. Sidorov, "Formation of luminescent and nonluminescent silver nanoparticles in silicate glasses by near-infrared femtosecond laser pulses and subsequent thermal treatment: the role of halogenides," Optical Engineering, 55(6), 067101-067101 (2016).

[90] F. Kompan, G. Venus, L. Glebova, H. Mingareev, L. Glebov, "Photo-thermo-refractive glass with sensitivity extended to near infrared region", Proc. SPIE 9744, Optical Components and Materials XIII, 97440I (24 February 2016).

[91] J. Lumeau, A. Sinitskiy, L. N. Glebova, L. B. Glebov and E. D. Zanotto, "Spontaneous and photo-induced crystallization of PTR glass", Physics and Chemistry of Glasses: European Journal of Glass Science and Technology Part B 48(4), 281-284 (2007).

[92] I. Dyamant, AV.M. Fokin, E.D. Zanotto, J. Lumeau, L.N. Glebova, L.B. Glebov, "On the thermal events during non-isothermal crystallization of photo-thermo-refractive glasses", in preparation (2016). 
[93] I. Dyamant, A.S. Abyzov, V.M. Fokin, E.D. Zanotto, J. Lumeau, L.N. Glebova, L.B. Glebov. "Crystal nucleation and growth kinetics of NaF in photo-thermo-refractive glass", Journal of Non-Crystalline Solids 378, 115-120 (2013).

[94] N. V. Nikonorov, A. I. Sidorov, V. A. Tsekhomskiň, K. E. Lazareva, "Effect of a dielectric shell of a silver nanoparticle on the spectral position of the plasmon resonance of the nanoparticle in photochromic glass", Condensed-Matter Spectroscopy Optics and Spectroscopy, 107-705 (2009).

[95] A. P. Nacharov, N. V. Nikonorov, A. I. Sidorov, V. A. Tsekhomskii, "Influence of ultraviolet irradiation and heat treatment on the morphology of silver nanoparticles in photothermorefractive glasses", Glass Physics and Chemistry 34, Issue 6, 693-699 (2008). [96] A. V. Vostokov, A. I. Ignat'ev, N. V. Nikonorov, O. A. Podsvirov, A. I. Sidorov, A. V. Nashchekin, R. V. Sokolov, O. A. Usov, V. A. Tsekhomskii, "Effect of electron irradiation on the formation of silver nanoclusters in photothermorefractive glasses", Technical Physics Letters $35,812(2009)$.

[97] V. D. Dubrovin, A. I. Ignatiev, V. M. Nevedomskii, N. V. Nikonorov, A. I. Sidorov, V. A. Tsekhomskii, "The influence of synthesis conditions and ultraviolet irradiation on the morphology and concentration of silver nanocrystals in photothermo-refractive glasses," Glass Technology-European Journal of Glass Science and Technology Part A 55 (6), C. 191-195 (2014).

[98] J. Lumeau, L. Glebova and L. B. Glebov, "Evolution of absorption spectra in the process of nucleation in photo-thermo-refractive glass", Advanced Materials Research, 39-40, 395-398 (2008). 
[99] L. Rycerz, M. Szymanska-Kolodziej, P. Kolodziej, and M. Gaune-Escard, "Thermodynamic properties of $\mathrm{AgCl}$ and $\mathrm{AgBr} "$, J. Chem. Eng. Data 53, 1116-1119 (2008).

[100] W. Luo, W. Hu, and S. Xiao, "Size effect on the thermodynamic properties of silver nanoparticles", J. Phys. Chem. C 112, 2359-2369 (2008).

[101] J. Lumeau, L. Glebova, G. P. Souza, E. D. Zanotto and L. B. Glebov "Effect of cooling on the optical properties and crystallization of UV-exposed photo-thermo-refractive glass", Journal of Non Crystalline Solids 354, 4730-4736 (2008).

[102] V. M. Fokin, G. P. Souza, E. D. Zanotto, J. Lumeau, L. Glebova, L. B. Glebov, "Sodium fluoride solubility in photo-thermo-refractive glass", Journal of the American Ceramic Society 93(3), 716-721 (2010).

[103] G. P. Souza, V. M. Fokin, E. D. Zanotto, J. Lumeau, L. Glebova, L. B. Glebov, "Micro and nanostructures in partially crystallized photo-thermo-refractive glass", Physics and Chemistry of Glasses: European Journal of Glass Science and Technology Part B 50 (5), 311-320 (2009).

[104] N. V. Nikonorov, E. I. Panysheva, I. V. Tunimanova, and A. V. Chukharev, "Influence of glass composition on the refractive index change upon photothermoinduced crystallization," Glass Phys. Chem. 27(3), 241-249 (2001).

[105] G. P. Souza, V. M. Fokin, C. A. Baptista, E. D. Zanotto, J. Lumeau, L. Glebova, L. B. Glebov, "Effect of bromine on NaF crystallization in photo-thermo-refractive glass", Journal of the American Ceramic Society 94(9), 2906-2911 (2011).

[106] G. P. Souza, V. M. Fokin, C. F. Rodrigues, A. C. M. Rodrigues, E. D. Zanotto, J. Lumeau, L. Glebova, L. B. Glebov, "Liquid-liquid phase separation in photo-thermo-refractive glass", Journal of the American Ceramic Society, 94(1), 145-150 (2011). 
[107] W. Haller, D. H. Blackburn, and J. H. Simmons, "Miscibility gaps in alkali-silicate binaries — Data and thermodynamic interpretation," J. Am. Ceram. Soc. 57(3), 120-6 (1974). [108] J. H. Markis, K. Clemens, and M. Tomozawa, ""Effect of fluorine on the phase separation of Na2O-SiO2 glasses," J. Am. Ceram. Soc. 64(1) C20 (1981).

[109] G. P. Souza, V. M. Fokin, E. D. Zanotto, J. Lumeau, L. Glebova and L. B. Glebov, "Microstructural evolution in photo-thermo-refractive (PTR) glass during crystallization", International Congress on Glass (Strasbourg, France), paper T14, July 2007.

[110] K. Chamma, J. Lumeau, L. Glebova, L. Glebov, "Mechanisms of NaF growth in photothermo-refractive glass", Glass and Optical material division, Spring 2011 Meeting (Savannah, Georgia, USA), paper GOMD- SIII- 014- 2011, May 2011.

[111] K. Chamma, J. Lumeau, L. Glebova, and L. Glebov, "X-ray diffraction study of NaF nanocrystals in photo-thermo-refractive glass", Journal of Non-Crystalline Solids 405, 188-195 (2014).

[112] L. Glebova, M. Klimov, K. Chamma, and L. Glebov, "Photo-structural transformations in photo-thermo-refractive glass", International Congress on Glass (Prague, Czech Republic), paper 171 , July 2013.

[113] J. W. Zwanziger, U. Werner-Zwanziger, E. D. Zanotto, E. Rotari, L. N. Glebova, L.B. Glebov and J. F. Schneider, "Residual internal stress in partially crystallized photo thermo refractive glass: Evaluation by nuclear magnetic resonance spectroscopy and first principles calculations," J. Appl. Phys. 99, 083511 (2006).

[114] F. C. Serbena, G. P. Souza, E. D. Zanotto, J. Lumeau, L. Glebova, L. B. Glebov, "Internal residual stress in partially crystallized photo-thermo-refractive glass", Journal of the American Ceramic Society, 94(3) 671-674 (2011). 
[115] J. Selsing, "Internal stresses in ceramics," J. Amer. Ceram. Soc. 44, 419 (1961).

[116] V. R. Mastelaro, E. D. Zanotto, "Residual stresses in a soda-lime-silica glass-ceramic," Journal of Non-Crystalline Solids 194(3), 297-304 (1996).

[117] A. G. Lanin, "Effect of residual stresses on the strength of ceramic materials (Review)," Russian Metallurgy (Metally) 2012(4), 307-322 (2012).

[118] L. Wondraczek, J. Mauro, J. Eckert, U. Kühn, J. Horbach, J. Deubener, and T. Rouxel, "Towards ultrastrong glasses", Adv. Mater. 23, 4578-4586 (2011).

[119] L.B. Glebov, "Kinetics modeling in photosensitive glass", Optical Materials 25(4), 413418 (2004).

[120] A.N. Kolmogorov, "On the statistical theory of crystallization of metals," Izv. Akad. Nauk. USSR, Ser. Matemat 1, 355 (1937).

[121] W.A. Johnson, and R.F. Mehl, "Reaction kinetics in processes of nucleation and growth", Trans. AIME 135, 416 (1939).

[122] M. Avrami, J. Chem., "Kinetics of phase change. I General theory", Phys. 7, 1103-1112 (1939).

[123] V. Fokin, E.D. Zanotto, N. Yuritsyn, and J.W. Schmelzer, "Homogeneous crystal nucleation in silicate glasses: A forty years perspective," Journal of Non Crystalline Solids 352, 2681-2714 (2006).

[124] J. Lumeau and L.B. Glebov, "Refractive index measurements in photo-thermo-refractive glass at different stages of hologram fabrication", 8th Pacific Rim Conference on Ceramic and Glass Technology (PACRIM 8) (Vancouver, British Columbia, Canada), paper PACRIM8-S25P205-2009, June 2009. 
[125] L. Glebova, J. Lumeau, M. Klimov, E. D. Zanotto and L. B. Glebov, "Role of bromine on the thermal and optical properties of photo-thermo-refractive glass", Journal of Non Crystalline Solids, 354, 456-461 (2008).

[126] O.M. Efimov, L.B. Glebov, H.P. Andre, "Measurement of the induced refractive index in a photothermorefractive glass by a liquid-cell shearing interferometer", Appl. Optics 41, 18641871 (2002).

[127] S. Stevic, R. Aleksic, N. Backovi, "Influence of fluorine on thermal properties of fluorophosphate glasses", J. Am. Ceram. Soc. 70, 1101 C-264-C-265 (1987).

[128] J. Lumeau, L. Glebova, V. Smirnov, M. Klimov and L. Glebov, "Mechanisms of photosensitivity in photo-thermo-refractive glass and volume Bragg gratings", Glass and Optical material division, Spring 2013 Meeting (San Diego, California, USA), paper PACRIM10-SC009-2013, May 2013 
Tables and Figures:

Table 1. Typical PTR glass composition.

\begin{tabular}{|l|r|r|}
\hline Elements & Wt. \% & Mol.\% \\
\hline $\mathbf{S i O}_{2}$ & 68.5 & 71.127 \\
\hline $\mathbf{A l}_{2} \mathbf{O}_{3}$ & 4.8 & 2.924 \\
\hline $\mathbf{N a}_{2} \mathbf{O}$ & 12.9 & 1.987 \\
\hline $\mathbf{Z n O}$ & 6.6 & 5.100 \\
\hline $\mathbf{N a F}$ & 4.3 & 6.362 \\
\hline $\mathbf{K B r}$ & 2.8 & 1.457 \\
\hline $\mathbf{A g}_{\mathbf{2}} \mathbf{O}$ & 0.02 & 0.006 \\
\hline $\mathbf{C e O}_{2}$ & 0.02 & 0.007 \\
\hline $\mathbf{S b}_{\mathbf{2}} \mathbf{O}_{3}$ & 0.1 & 0.021 \\
\hline $\mathbf{S n O}_{\mathbf{2}}$ & 0.02 & 0.008 \\
\hline & & \\
\hline
\end{tabular}


Table 2. Parameters of the Gaussian bands of cerium absorption spectra in a standard PTR glass (from [65]). $\mathrm{A}^{0}{ }_{\mathrm{i}}$ is the specific absorption of cerium in the maximum of a Gaussian band, $\sigma_{\mathrm{i}}$ the central wave number, $\lambda_{\mathrm{i}}$ the central wavelength, and $\mathrm{W}_{\mathrm{i}}$, the full width at half maximum.

\begin{tabular}{|c|c|c|c|c|}
\hline Band \# & $\mathrm{A}_{\mathrm{i}}^{0}\left(\mathrm{~cm}^{-1} / \mathrm{at} . \%\right)$ & $\sigma_{\mathrm{i}}\left(\mathrm{cm}^{-1}\right)$ & $\lambda_{\mathrm{i}}(\mathrm{nm})$ & $\mathrm{W}_{\mathrm{i}}\left(\mathrm{cm}^{-1}\right)$ \\
\hline $\mathrm{Ce}^{3+/ 1}$ & 126.8 & $32045 \pm 10$ & $312 \pm 0.1$ & $1542.4 \pm 0.5$ \\
\hline $\mathrm{Ce}^{3+/ 2}$ & 246.3 & $33059 \pm 10$ & $302 \pm 0.1$ & $2072.3 \pm 0.5$ \\
\hline $\mathrm{Ce}^{4+/ 1}$ & 1148.5 & $40045 \pm 10$ & $250 \pm 0.1$ & $5278.0 \pm 0.5$ \\
\hline \hline $\mathrm{Ce}^{4+/ 2}$ & 835.5 & $47488 \pm 20$ & $211 \pm 0.2$ & $6458.0 \pm 1.0$ \\
\hline
\end{tabular}


Table 3. Central frequencies of the Gaussian bands of cerium absorption spectra in a standard PTR glass (from [77-79]).

\begin{tabular}{|c|c|c|}
\hline $\begin{array}{c}\text { Valence } \\
\text { state }\end{array}$ & Spectral components & $\begin{array}{c}\text { Frequencies of } \\
\text { components, } \mathbf{c m}^{-\mathbf{1}}\end{array}$ \\
\hline $\mathbf{C e}^{\mathbf{3 +}}$ & $\mathrm{Ce}^{3+}(1)$ & 31000 \\
\hline & $\mathrm{Ce}^{3+}(2)$ & 32663 \\
\hline & $\mathrm{Ce}^{3+}(3)$ & 34876 \\
\hline $\mathbf{C e}^{\mathbf{4 +}}$ & $\mathrm{Ce}^{4+}(1)$ & 38764 \\
\hline & $\mathrm{Ce}^{4+}(2)$ & 44351 \\
\hline & $\mathrm{Ce}^{4+}(3)$ & 48750 \\
\hline
\end{tabular}


Table 4. Evolution of the volume fraction, crystal diameter, and crystal number density as a function of thermal treatment duration at $515^{\circ} \mathrm{C}$ in PTR glass UV-exposed with $0.9 \mathrm{~J} / \mathrm{cm}^{2}$ (from [111]).

\begin{tabular}{|c|c|c|c|}
$\begin{array}{c}\text { Thermal } \\
\text { treatment } \\
\text { duration, hours }\end{array}$ & $\begin{array}{c}\text { Volume } \\
\text { fraction, } \\
\text { vol.\% }\end{array}$ & $\begin{array}{c}\text { Crystal } \\
\text { diameter, } \\
\mathbf{n m}\end{array}$ & $\begin{array}{c}\text { Number of } \\
\text { crystals per } \\
\mathbf{m}^{\mathbf{3}}\end{array}$ \\
\hline $\mathbf{1}$ & 0.47 & 15.8 & $2.3 \mathrm{E}+21$ \\
\hline $\mathbf{1 . 5}$ & 0.54 & 17.0 & $2.1 \mathrm{E}+21$ \\
\hline $\mathbf{2}$ & 0.82 & 17.0 & $3.2 \mathrm{E}+21$ \\
\hline $\mathbf{3}$ & 1.12 & 17.3 & $4.1 \mathrm{E}+21$ \\
\hline $\mathbf{4}$ & 1.27 & 17.6 & $4.4 \mathrm{E}+21$ \\
\hline $\mathbf{5}$ & 1.33 & 18.0 & $4.4 \mathrm{E}+21$ \\
\hline $\mathbf{6}$ & 1.45 & 18.3 & $4.5 \mathrm{E}+21$ \\
\hline $\mathbf{1 2}$ & 1.61 & 18.7 & $4.7 \mathrm{E}+21$ \\
\hline $\mathbf{2 4}$ & 1.83 & 19.1 & $5.0 \mathrm{E}+21$ \\
\hline $\mathbf{3 2}$ & 1.91 & 19.6 & $4.9 \mathrm{E}+21$ \\
\hline $\mathbf{7 2}$ & 2.06 & 19.9 & $5.0 \mathrm{E}+21$ \\
\hline
\end{tabular}



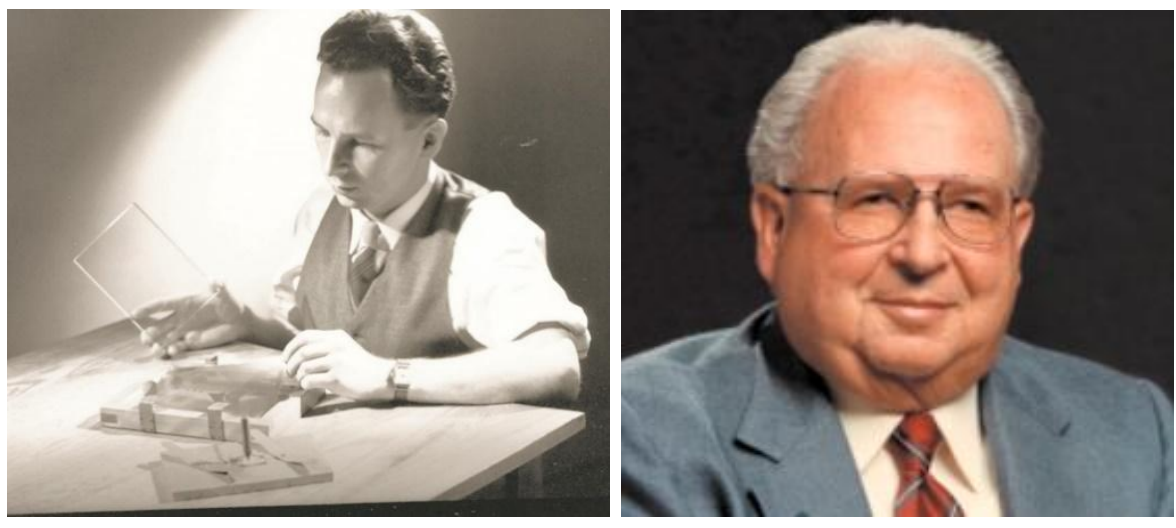

Figure 1. S. D. Stookey, inventor of photo-thermo-induced crystallization in multicomponent fluor-silicate glasses. 


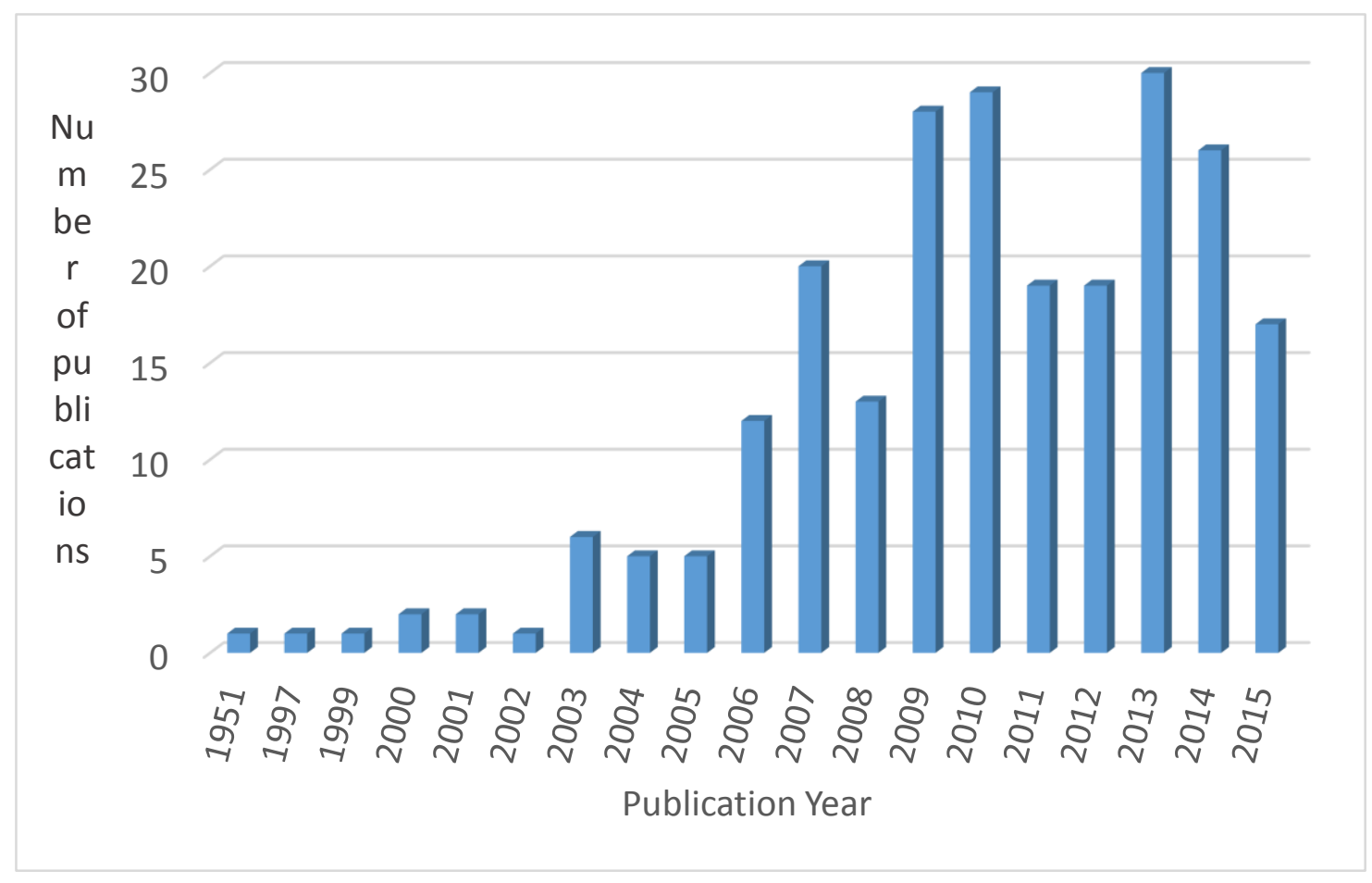

Figure 2. Number of papers published since 1951 with the keywords ("Photo-thermo-refractive" OR PTR) and Glass* in the article title, abstract or keyword. Source Scopus database. 


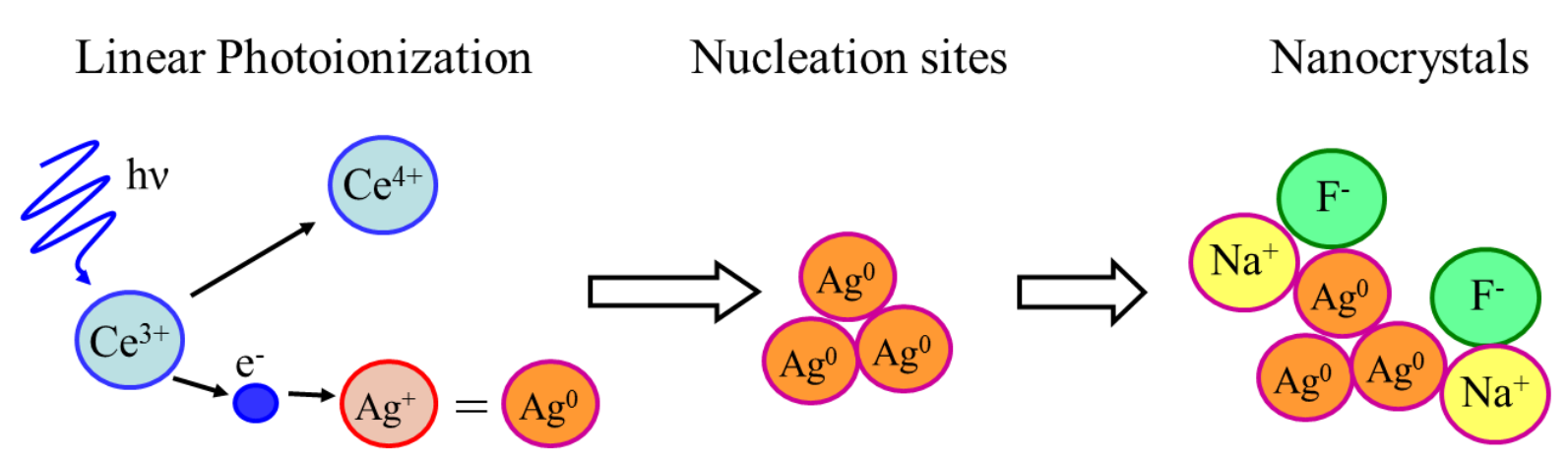

Figure 3. Cartoon of the classical mechanism that has been extensively used to explain the photo-thermo-induced structural transformations in PTR glass. We believe this cartoon is not correct. Recent electron microscopy work by Leonid Glebov's group [personal communication], show that the NaF crystals are not aligned (as they should be) in UV-exposed, thermally treated commercial PTRG gratings. 


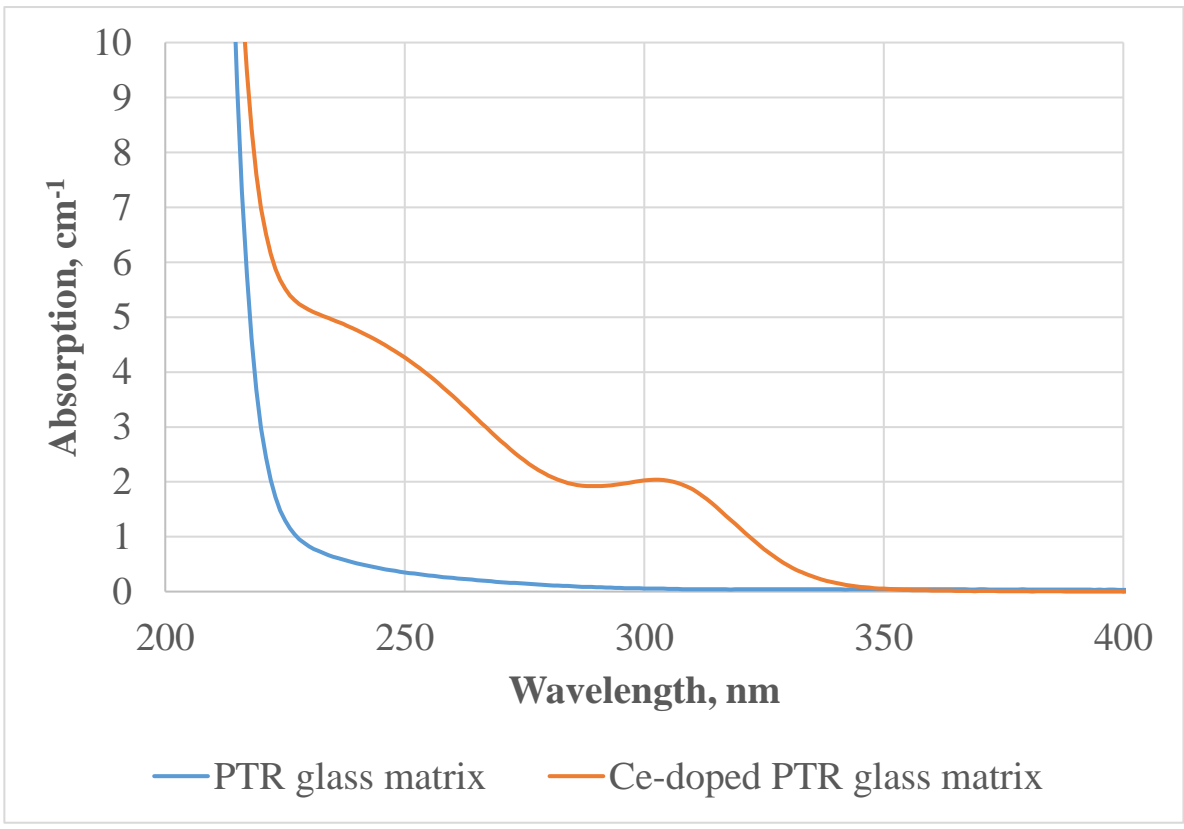

Figure 4. Absorption spectra of undoped and cerium doped pristine PTR glass matrix before any exposure and thermal treatment [65] 


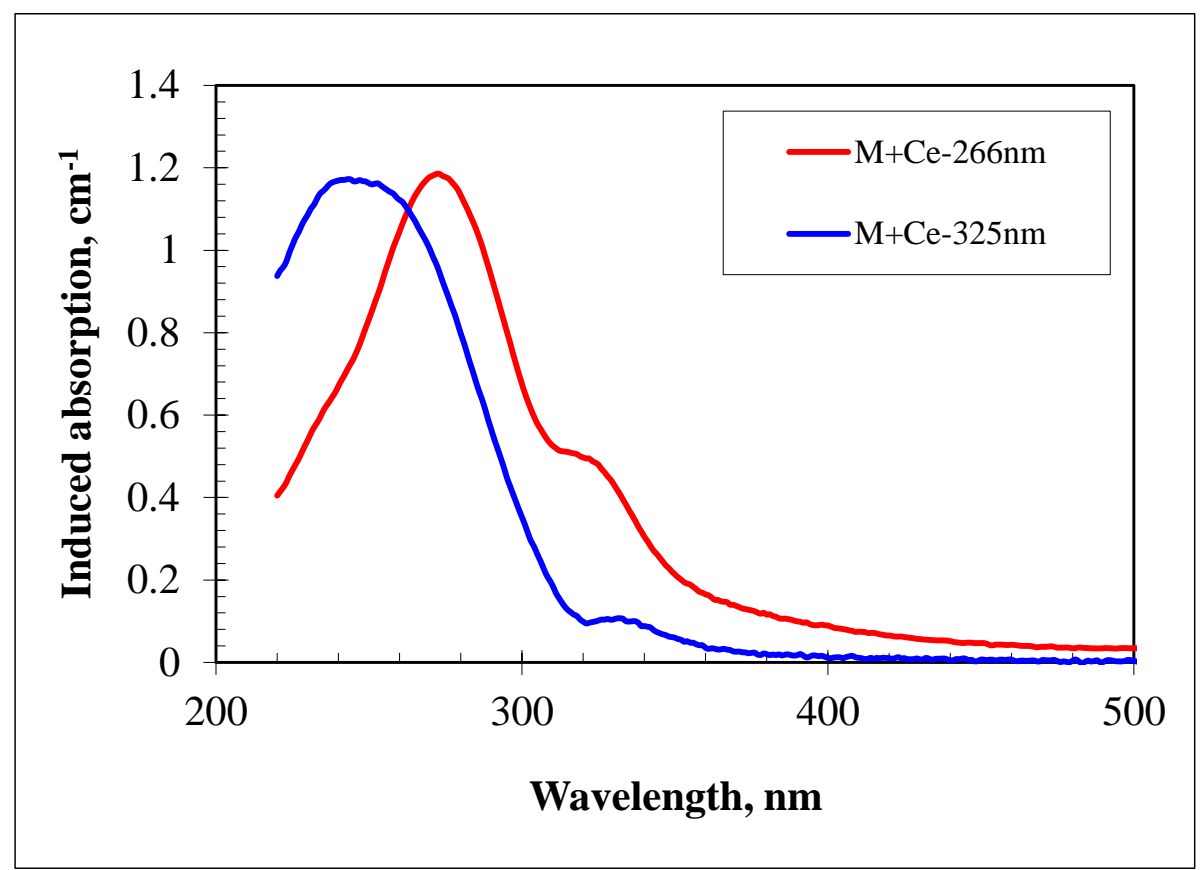

Figure 5. Induced absorption spectra of Cerium doped PTR glass matrix after exposure at 266 and $325 \mathrm{~nm}[83]$. 


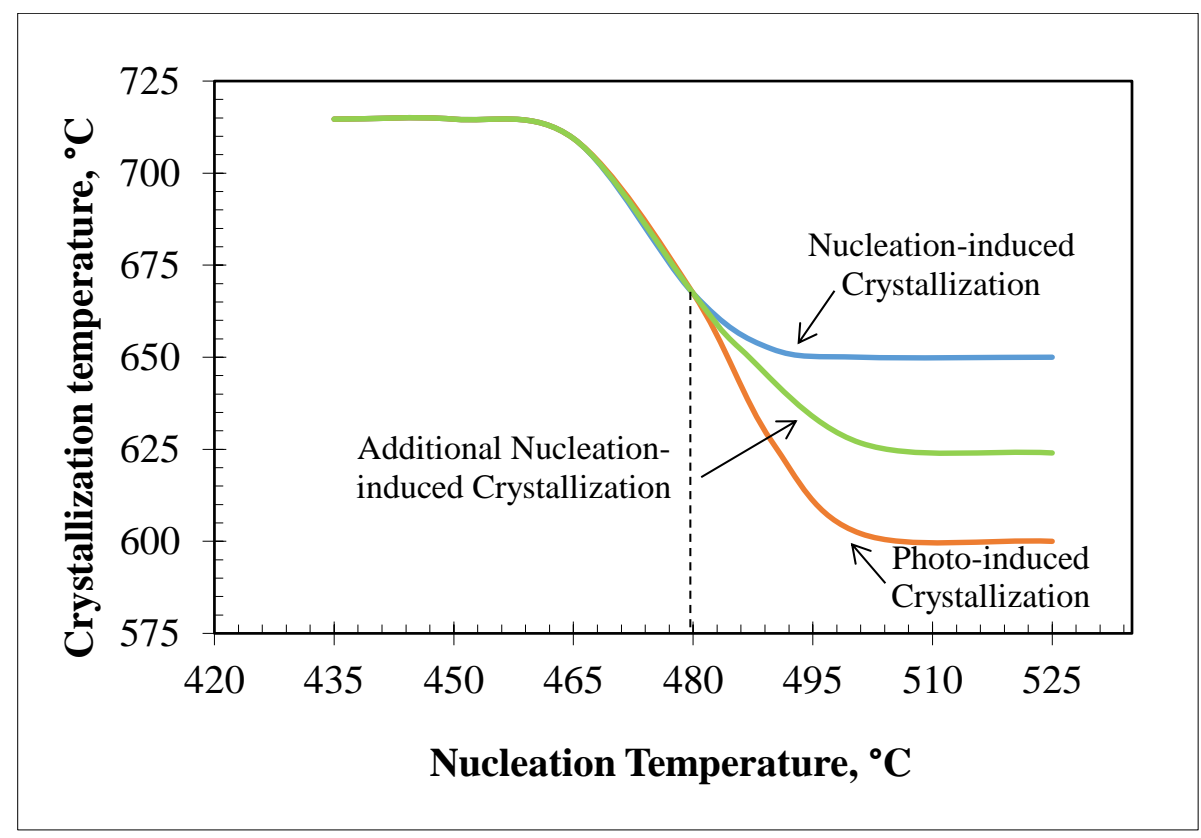

Figure 6. Dependence of crystallization peak temperature versus nucleation temperature of virgin and UV-exposed PTR glass determined from non-isothermal DSC experiments. The nucleation time before the DSC runs was 30 min [91]. 

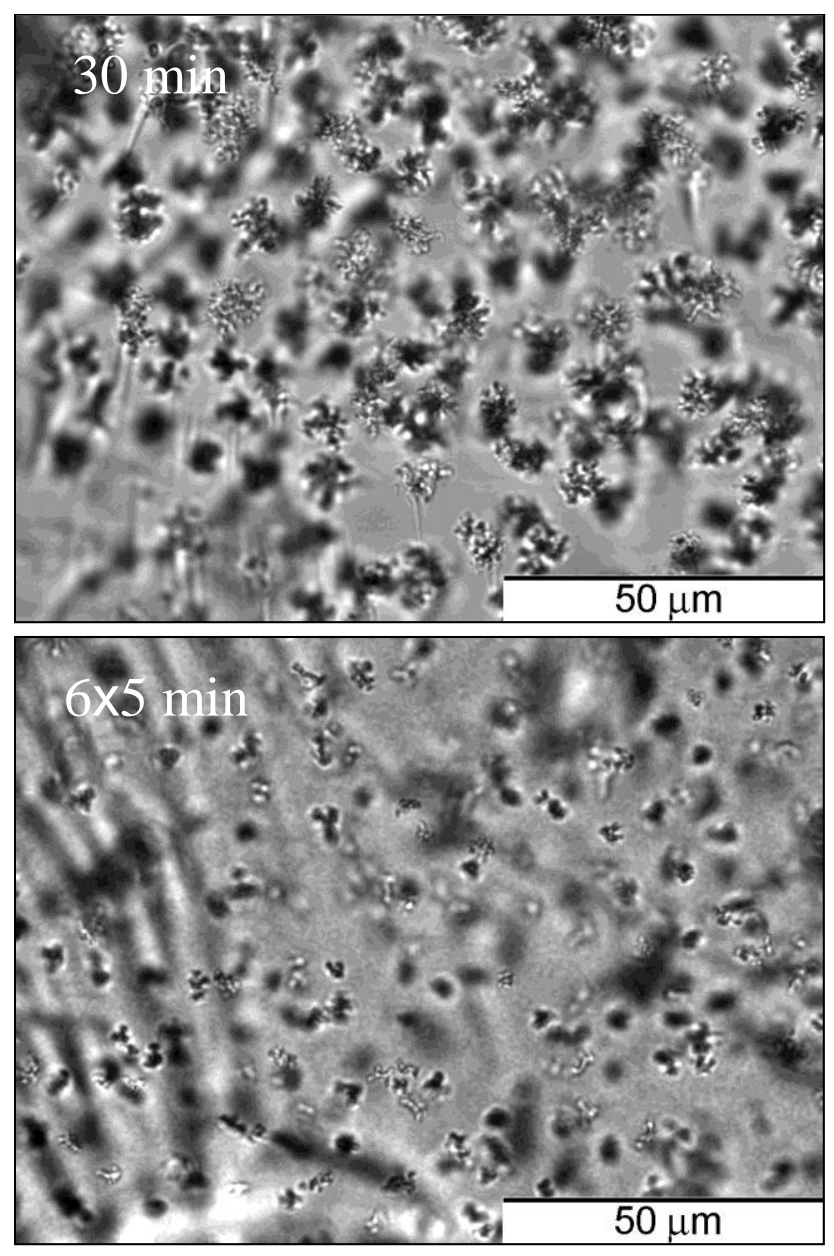

Figure 7. Optical micrographs of UV-exposed PTR glass treated for $30 \mathrm{~min}$ at $650{ }^{\circ} \mathrm{C}-(\mathrm{A})$ continuous heat-treatment and (B) multi-step heat-treatment [101]. 


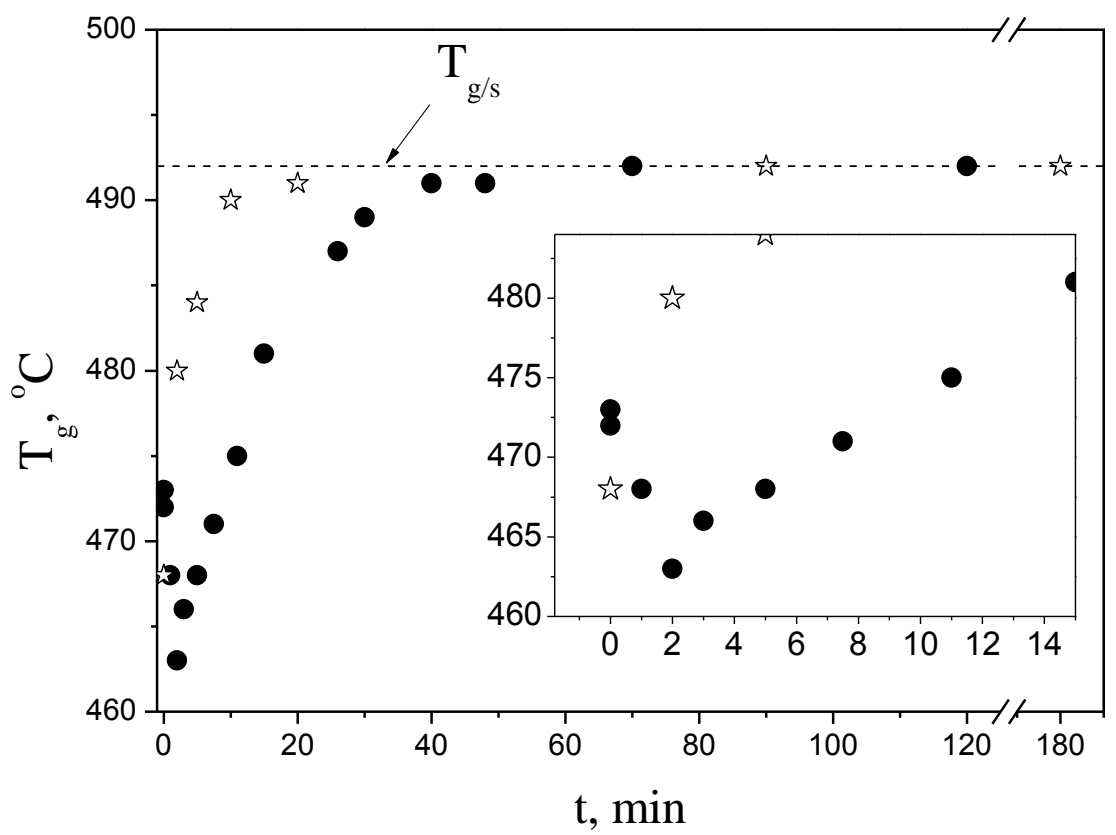

Figure 8. Glass transition temperature, $T_{g}$, determined from DSC traces as a function of heat treatment time at $650{ }^{\circ} \mathrm{C}$ for the original samples $(\bullet)$ and for samples previously nucleated at 480 ${ }^{\circ} \mathrm{C}$ for $35 \mathrm{~min}$ (ঊ). The first 15 min of treatment are shown in the inset [102]. 


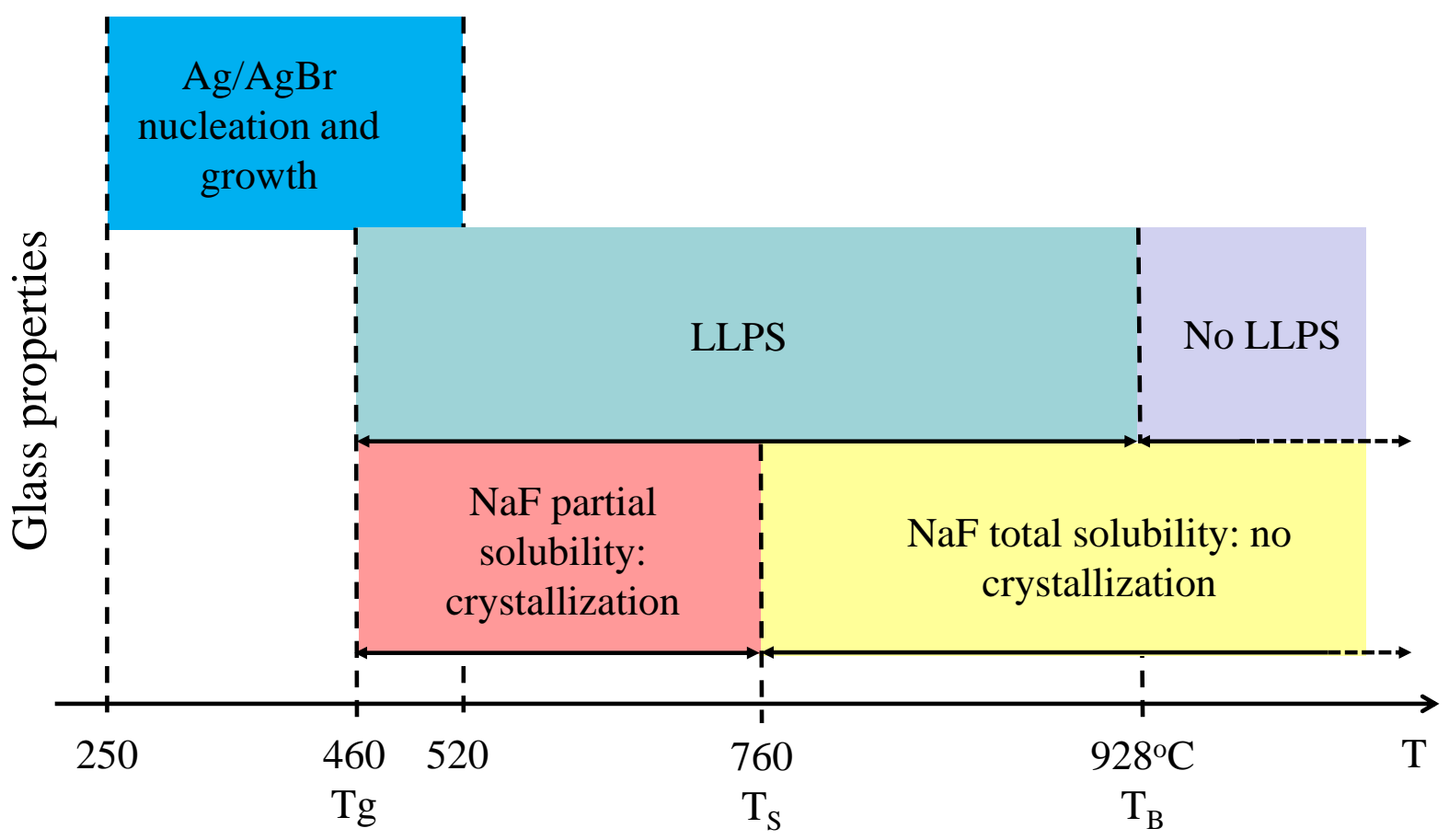

Figure 9. Temperature dependence of $\mathrm{NaF}$ solubility and Liquid-Liquid Phase Separation (LLPS) in PTR glasses. 

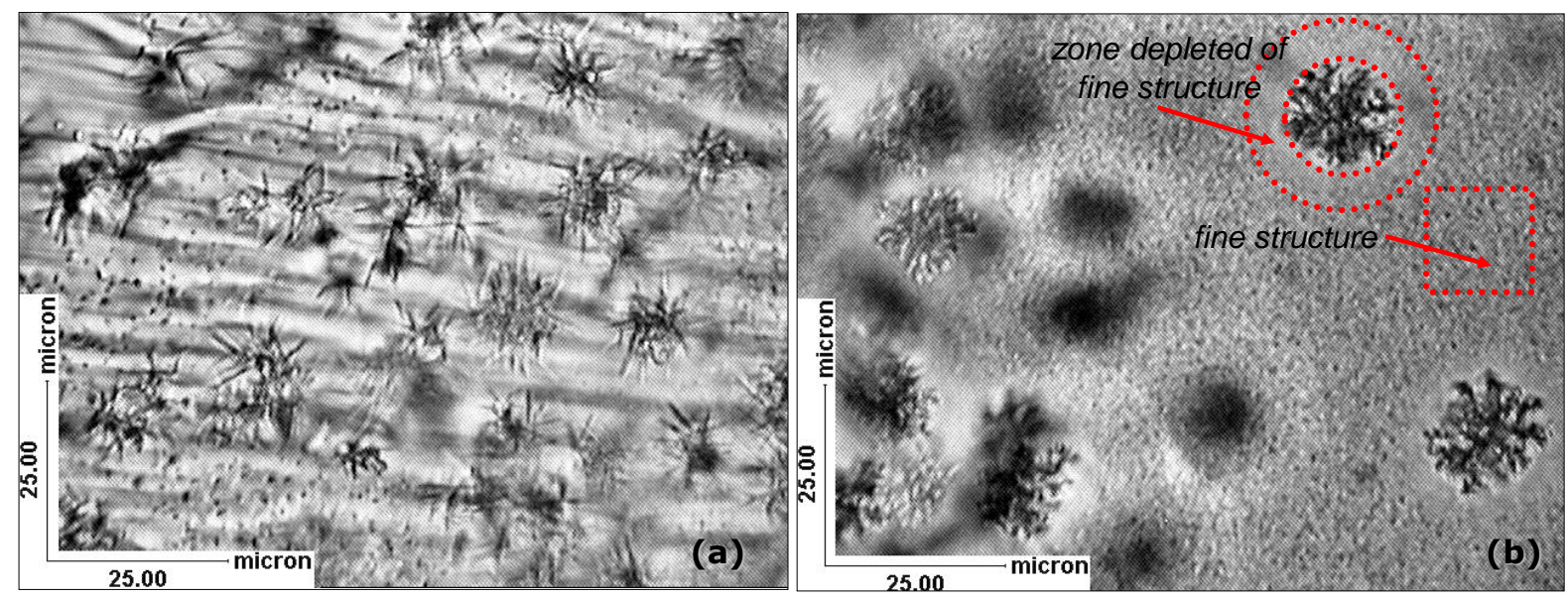

Figure 10. (a) and (b) are transmitted-light optical micrographs of as-cast PTR glass heat-treated at $650^{\circ} \mathrm{C}$ for $210 \mathrm{~min}$. The morphology of the dendrites resembles that of "spikes" in the unexposed sample (a), and "snowflakes" in the UV-exposed sample (b) [109]. 


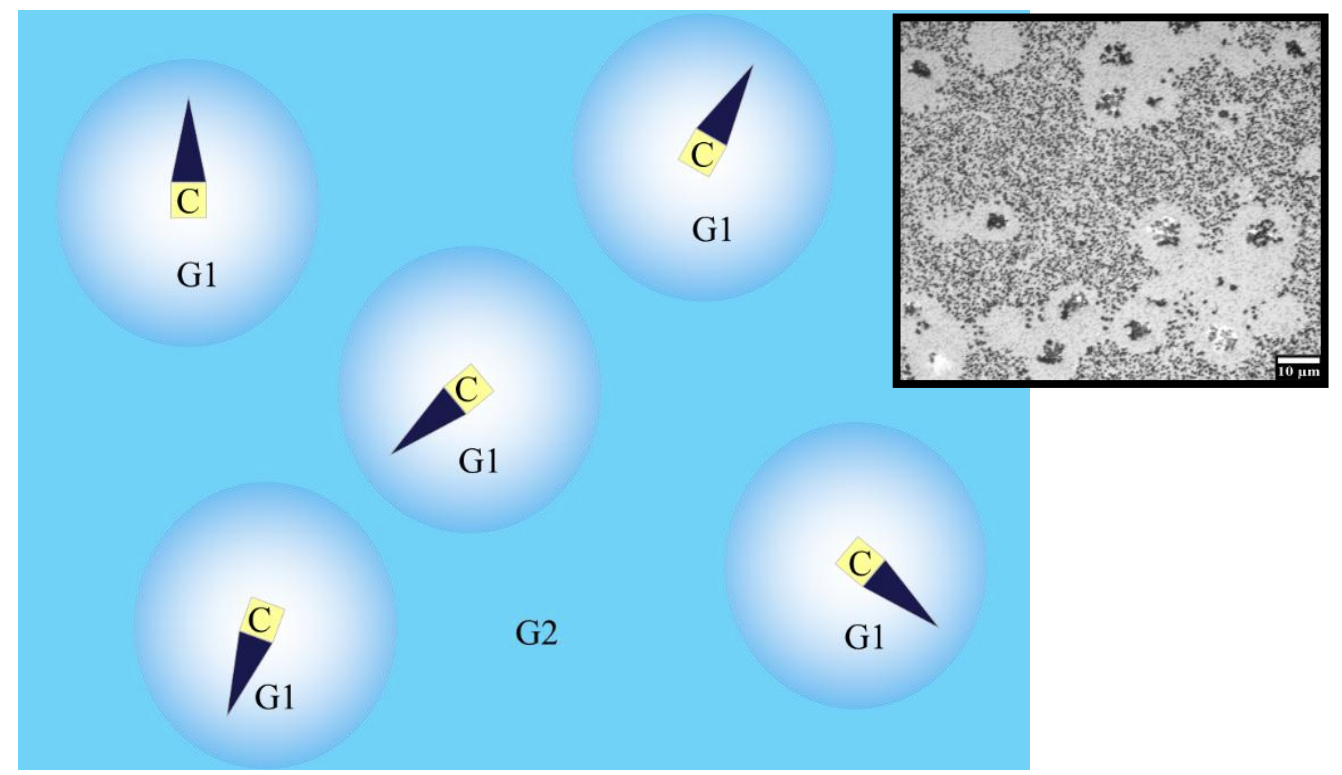

Figure 11. Illustration of the final three-phase structure of PTR glass after successive UVexposure and thermal treatment. The figure on the LHS is a drawing showing the NaF crystals (C), the $\mathrm{Na}^{+} \mathrm{F}^{-}$depleted glass (G1) and the unperturbed glass (G2). The Figure on the RHS is an optical microscope image of a hyper-developed PTR glass sample showing the NaF depleted courtyards surrounding the NaF crystals (from [72]). 


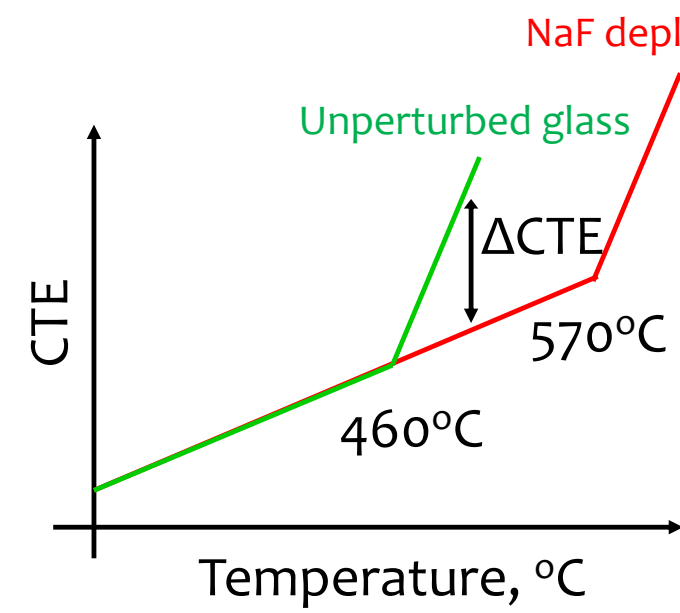

Figure 12. Illustration of the dependence of the coefficient of thermal expansions of the different areas of PTR glass. 


\section{List of Tables and Figures captions}

Table 1. Typical PTR glass composition.

Table 2. Parameters of the Gaussian bands of cerium absorption spectra in a standard PTR glass (from [67]). $\mathrm{A}_{\mathrm{i}}^{0}$ is the specific absorption of cerium in the maximum of a Gaussian band, $\sigma_{\mathrm{i}}$ the central wave number, $\lambda_{\mathrm{i}}$ the central wavelength, and $\mathrm{W}_{\mathrm{i}}$, the full width at half maximum.

Table 3. Central frequencies of the Gaussian bands of cerium absorption spectra in a standard PTR glass (from [77-79]).

Table 4. Evolution of the volume fraction, crystal diameter, and crystal number density as a function of thermal treatment duration at $515^{\circ} \mathrm{C}$ in PTR glass UV-exposed with $0.9 \mathrm{~J} / \mathrm{cm}^{2}$ (from [111]).

Figure 1. S. D. Stookey, inventor of photo-thermo-induced crystallization in multicomponent fluor-silicate glasses.

Figure 2. Number of papers published since 1951 with the keywords ("Photo-thermo-refractive" OR PTR) and Glass* in the article title, abstract or keyword. Source Scopus database.

Figure 3. Cartoon of the classical mechanism that has been extensively used to explain the photo-thermo-induced structural transformations in PTR glass. We believe this cartoon is not correct. Recent electron microscopy work by Leonid Glebov's group [personal communication], 
show that the NaF crystals are not aligned (as they should be) in UV-exposed, thermally treated commercial PTRG gratings.

Figure 4. Absorption spectra of undoped and cerium doped pristine PTR glass matrix before any exposure and thermal treatment [65]

Figure 5. Induced absorption spectra of Cerium doped PTR glass matrix after exposure at 266 and $325 \mathrm{~nm}$ [83].

Figure 6. Dependence of crystallization peak temperature versus nucleation temperature of virgin and UV-exposed PTR glass determined from non-isothermal DSC experiments. The nucleation time before the DSC runs was $30 \min [91]$.

Figure 7. Optical micrographs of UV-exposed PTR glass treated for $30 \mathrm{~min}$ at $650{ }^{\circ} \mathrm{C}-(\mathrm{A})$ continuous heat-treatment and (B) multi-step heat-treatment [101].

Figure 8. Glass transition temperature, $T_{g}$, determined from DSC traces as a function of heat treatment time at $650^{\circ} \mathrm{C}$ for the original samples $(\bullet)$ and for samples previously nucleated at 480 ${ }^{\circ} \mathrm{C}$ for $35 \mathrm{~min}(\star)$. The first $15 \mathrm{~min}$ of treatment are shown in the inset [102].

Figure 9. Temperature dependence of $\mathrm{NaF}$ solubility and Liquid-Liquid Phase Separation (LLPS) in PTR glasses. 
Figure 10. (a) and (b) are transmitted-light optical micrographs of as-cast PTR glass heat-treated at $650^{\circ} \mathrm{C}$ for $210 \mathrm{~min}$. The morphology of the dendrites resembles that of "spikes" in the unexposed sample (a), and "snowflakes" in the UV-exposed sample (b) [109].

Figure 11. Illustration of the final three-phase structure of PTR glass after successive UVexposure and thermal treatment. The figure on the LHS is a drawing showing the NaF crystals (C), the $\mathrm{Na}^{+} \mathrm{F}^{-}$depleted glass (G1) and the unperturbed glass (G2). The Figure on the RHS is an optical microscope image of a hyper-developed PTR glass sample showing the NaF depleted courtyards surrounding the NaF crystals (from [72]).

Figure 12. Illustration of the dependence of the coefficient of thermal expansions of the different areas of PTR glass. 